Review Article

\title{
The Prospect of Identifying Resistance Mechanisms for Castrate-Resistant Prostate Cancer Using Circulating Tumor Cells: Is Epithelial-to-Mesenchymal Transition a Key Player?
}

\author{
Tanzila Khan $\mathbb{D}^{1},{ }^{1,2,3}$ Kieran F. Scott ${ }^{D}$, ${ }^{1,2}$ Therese M. Becker ${ }^{1},{ }^{1,2,3,4}$ John Lock, ${ }^{5}$ \\ Mohammed Nimir, ${ }^{2,3,4,6}$ Yafeng $\mathrm{Ma}^{2,3,4}$ and Paul de Souza ${ }^{1,2,3,6,7}$ \\ ${ }^{1}$ School of Medicine, Western Sydney University, Campbelltown, NSW 2560, Australia \\ ${ }^{2}$ Medical Oncology, Ingham Institute of Applied Medical Research, Liverpool, NSW 2170, Australia \\ ${ }^{3}$ Centre of Circulating Tumour Cells Diagnostics \& Research, Ingham Institute of Applied Medical Research, Liverpool, \\ NSW 2170, Australia \\ ${ }^{4}$ South West Sydney Clinical School, University of New South Wales, Liverpool Hospital, Liverpool, NSW 2170, Australia \\ ${ }^{5}$ School of Medical Sciences, University of New South Wales, Kensington, Australia \\ ${ }^{6}$ Medical Oncology, Liverpool Hospital, Liverpool, NSW 2170, Australia \\ ${ }^{7}$ School of Medicine, University of Wollongong, Wollongong, NSW 2522, Australia
}

Correspondence should be addressed to Tanzila Khan; 19153083@student.westernsydney.edu.au

Received 3 September 2019; Revised 19 November 2019; Accepted 14 February 2020; Published 30 March 2020

Academic Editor: Craig Robson

Copyright $(\odot 2020$ Tanzila Khan et al. This is an open access article distributed under the Creative Commons Attribution License, which permits unrestricted use, distribution, and reproduction in any medium, provided the original work is properly cited.

Prostate cancer (PCa) is initially driven by excessive androgen receptor (AR) signaling with androgen deprivation therapy (ADT) being a major therapeutic approach to its treatment. However, the development of drug resistance is a significant limitation on the effectiveness of both first-line and more recently developed second-line ADTs. There is a need then to study AR signaling within the context of other oncogenic signaling pathways that likely mediate this resistance. This review focuses on interactions between AR signaling, the well-known phosphatidylinositol-3-kinase/AKT pathway, and an emerging mediator of these pathways, the Hippo/YAP1 axis in metastatic castrate-resistant PCa, and their involvement in the regulation of epithelial-mesenchymal transition (EMT), a feature of disease progression and ADT resistance. Analysis of these pathways in circulating tumor cells (CTCs) may provide an opportunity to evaluate their utility as biomarkers and address their importance in the development of resistance to current ADT with potential to guide future therapies.

\section{Introduction}

Prostate cancer ( $\mathrm{PCa}$ ) is highly prevalent in the Western world; it ranks sixth among cancers in regard to mortality among men [1]. There were 1,276,106 new cases of PCa and 358, 989 deaths due to PCa worldwide in 2018 [2]. Despite dramatic improvements in five-year survival, mortality from $\mathrm{PCa}$ is poised to remain a major health problem due to increasing longevity, particularly in western countries. The most significant factors associated with morbidity and mortality are the development of metastatic spread to other organs, particularly bone, and emerging resistance to therapy.
On the molecular level, PCa is almost always initially driven by excessive signaling through the androgen receptor (AR) pathway (reviewed in [3]). Consequently, men with metastatic PCa will be offered androgen deprivation therapy (ADT) as the primary treatment. After a median of around 18-24 months, the disease tends to become resistant to hormonal manipulation and progresses towards so-called metastatic castration-resistant prostate cancer (mCRPC). In mCRPC, the concentration of the current blood-based clinical PCa biomarker, prostate-specific antigen (PSA), continues to increase over time. As PSA is regulated via AR signaling, this suggests, in general, the common ongoing 
involvement of $\mathrm{AR}$ signaling in disease progression to mCRPC [4-7]. Abiraterone [8,9] and enzalutamide [10, 11] have been developed to be used for mCRPC, as "secondgeneration" ADT treatments, and responses are generally good, but a median progression-free survival of 5.6 months [8] suggests resistance to treatment once again supervenes. Indeed, despite the difference in mechanisms of action, cross-resistance between enzalutamide and abiraterone is very common $[8,12-14]$, suggesting the development of true hormone resistance following second-line ADT therapy, as opposed to castrate resistance. Thus, androgen signaling through AR within the context of the oncogenic effect of other signaling pathways remains an important area of research as there are, yet, no effective treatments or markers for true hormone resistance. Here, we review the involvement of two critical signaling pathways, the phosphatidylinositol-3-kinase/AKT (PI3K/AKT) and Hippo/YAP pathway, which interact with the AR pathway in mCRPC and which have links to epithelial-to-mesenchymal transition (EMT). EMT is thought to play an important role in the development of both metastasis and therapy resistance $[15,16]$. Our literature research indicates that the analysis of circulating tumor cells (CTCs) isolated from PCa patients may allow CTCs to be used as a tool to define how these signaling pathways interact with the AR pathway to cause $\mathrm{ADT}$ resistance and thereby investigate the mechanism by which these pathways may contribute to castrate resistance. In addition, CTCs may thus emerge as a useful PCa biomarker for personalized therapy.

\section{Circulating Tumor Cells and EMT in Metastasis}

Metastasis in PCa is integrally linked to mCRPC. At the cellular level, metastasis involves a sequence of steps, and current evidence suggests that EMT and the reverse process mesenchymal-to-epithelial transition (MET) (reviewed in [17]) are important mechanisms by which tumor cells migrate and reestablish themselves at distant sites. Cancer cells are believed to lose their tight adhesion to neighboring cells and become more mobile when undergoing EMT, which, in turn, favors their ability to shed from the tumor mass, intravasate into the bloodstream, and thus become CTCs. MET, on the other hand, is thought to aid CTCs after leaving the vascular system to be able to settle in other tissues and form new tumors $[18,19]$ (Figure 1). Thus, CTC numbers have been recognized as a marker of metastatic disease, and importantly, EMT markers have been screened for in patient CTCs including those of 54 patients with $\mathrm{PCa}, 53 \%$ of these patients had advanced metastatic disease and intermittent epithelial-to-mesenchymal phenotype of CTCs correlated with metastasis in these patients, while another study found that the mesenchymal CTC phenotype correlated with increased rates of progression to CRPC in a cohort of $108 \mathrm{PCa}$ patients recruited with high volume metastatic disease at hormone-sensitive disease stage and longitudinally followed during the study [20-22].

Metastatic spread of cancer is thought to involve different stages (Figure 1(a)) in which cancer cells (i) lose cell- cell tight junctions and detach from the primary site/organ, (ii) penetrate the basal lamina and enter nearby tissue, (iii) evade programmed cell death normally induced by loss of substrate adhesion (anoikis), (iv) breach blood or lymphatic vessels and migrate to other sites via blood/lymphatic circulation, (v) leave the bloodstream or lymphatic vessels at distant organs, (vi) form a micrometastatic core, and finally (vii) adjust and reprogram the surrounding stroma to form detectable macrometastases [23]. At a molecular level, EMT has been implicated in various cancers, including PCa. In the development of mCRPC, it has been proposed that activation of transcription factors (TFs) results in the loss of epithelial properties and acquisition of mesenchymal characteristics as well as the change of cell shape, leading to enhanced invasion and increased mortality [24, 25].

EMT is inducible by environmental factors such as radiation or hypoxia (Figure 1(b)), and there is accumulating evidence that radiation or chemotherapy, used to treat earlier stage PCa, may induce EMT changes [26, 27]. Hypoxia induces the production of hypoxia-inducible factor (HIF), and HIF- $1 \alpha$ stimulates transcription factors (TFs), such as Snail and Twist, to trigger EMT [28, 29]. EMT then results from activation of a mesenchymal transcriptional program induced by specific transcription factors (EMTTFs) [26]. Mechanistically, central EMT-TFs ZEB1, Snail, Slug, and Twist along with other TFs such as TCF4 and FOXC2 suppress the expression of key epithelial markers such as cytokeratin, E-cadherin, occludin, and claudin while causing upregulation of mesenchymal markers such as $\mathrm{N}$-cadherin, fibronectin, and vimentin, which enable cancer cells to be more motile and consequently more aggressive (Figure 1(c)).

Regulation by signaling cascades and signaling molecules including EGF, Hedgehog, Wnt, FGF, Notch, TGF- $\beta$, and HGF in turn induces signaling via NF- $\kappa \mathrm{B}, \mathrm{MAPK}, \mathrm{PI} 3 \mathrm{~K} /$ $\mathrm{AKT}$, or Wnt/ $\beta$-catenin pathways to regulate EMT-TFs and ultimately induce EMT phenotypic changes. More recently, the Hippo pathway has been implicated in regulating EMT via its downstream transcriptional modulator Yes-associated protein (YAP) and the transcriptional coactivator TAZ $[28,30-38]$. Importantly, there is evidence in the literature that these pathways can be successfully analysed in CTCs even though in some cases these analyses may not have yet been reported for PCa CTCs. Table 1 summarises some of the evidence implicating signaling pathways in EMT of PCa as well as the analysis of these pathways in CTCs mainly from other cancers. CTC studies from other cancers are included because they indicate the feasibility of investigating these pathways in PCa CTC.

\section{Clinical Relevance of EMT Markers in PCa}

Several studies have assessed EMT markers for their clinical importance at various stages of human PCa. Table 2 shows typical EMT markers detected in PCa tissue. A possible clinical utility of these EMT markers at different phases of the disease is suggested by their prognostic correlation with both recurrence-free and overall survival. For example, EMT markers Twist and vimentin as measured by 


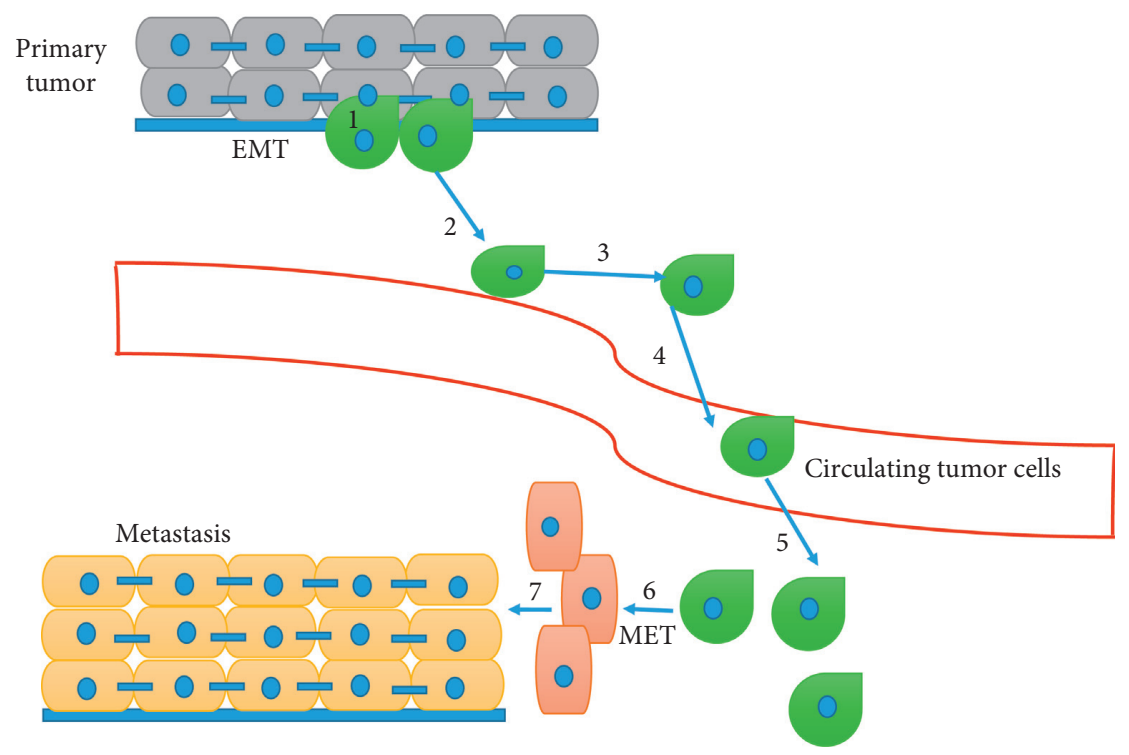

(1) Detachment and movement from the primary site/organ

(2) Invasion into nearby organ

(3) Evade programmed cell death after detachment from the primary site

(4) Invasation in the blood or lymphatic vessel

(5) Extravasation of the blood stream/lymphatic vessel at a distant organ

(6) Form a micrometastatic nodule

(7) Form macrometastasis

(a)

\begin{tabular}{ll|l}
\cline { 2 - 3 } $\begin{array}{l}\text { Environmental } \\
\text { factors }\end{array}$ & Signaling molecules & Signaling cascades \\
$\begin{array}{l}\text { Hypoxia } \\
\text { Radiation }\end{array}$ & EGF, Hedgehog, & Notch, NF-KB, Hippo, \\
Wnt, FGF, Notch, TGF- $\beta$, & $\begin{array}{l}\text { MAPK, AKT, Wnt } / \beta- \\
\text { catenin, AR }\end{array}$ \\
\hline
\end{tabular}

(b)

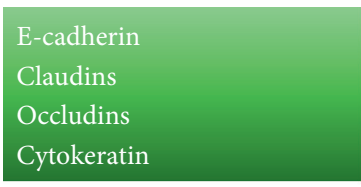

Epithelial cells

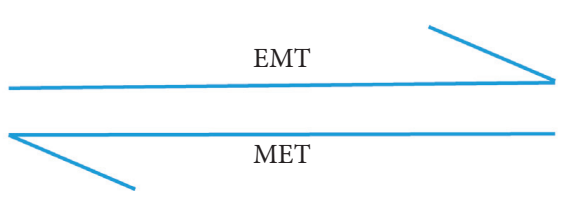

Transcription regulators/coactivators

ZEB1, TCF4, YAP1, Snail 1, Twist, FOXC2, and Snail 2

GURE 1: EMT in cancer metastasis. (a) Schematic representation of the role of EMT in cancer metastasis. (b) A cascade of transcriptiona regulation underlies the transition from an epithelial to a mesenchymal phenotype, and (c) during EMT, epithelial markers are downregulated while mesenchymal markers are upregulated.

immunohistochemistry in radical prostatectomy samples are independent markers for biochemical recurrence as defined by a resurgence in serum prostate-specific antigen (PSA) levels postsurgery $[84,90]$. A recent study found that Cathepsin L (Cat L), which is an EMT-associated target of the EMT-TF Snail, may be a biomarker of PCa progression [83]. In addition, loss of membrane-bound E-cadherin staining appears to be linked with higher Gleason score, advanced clinical stage, and poor prognosis in PCa [91]. EMT markers such as Zeb1, E-cadherin, and vimentin play important roles at different stages of disease progression from primary tumor stage 2 to CRPC. In CRPC, increased expression of Zeb1 correlated with decreased survival [84]. Further, in a study of
108 patients with newly diagnosed castrate-sensitive $\mathrm{PCa}$, expression of mesenchymal markers in CTCs at baseline was found to be an independent prognostic factor that was predictive of time to progression to CRPC following standard ADT. Patients who had mesenchymal CTCs at baseline showed a significantly shorter time to progression to CRPC than patients without CTCs or patients whose CTCs were negative for mesenchymal markers [21]. Several studies show that E-cadherin suppresses invasion and metastasis in vitro, and consistent with these findings, E-cadherin staining in tumor tissue correlates with longer overall survival [84]. However, the relationship of E-cadherin to metastasis is not clear in all cases since, in a recent study, it has been shown that 
TABLE 1: Signaling pathways implicated in EMT and relevance to PCa.

\begin{tabular}{|c|c|c|c|}
\hline Pathway & Implication in cancer-related EMT & Roles in $\mathrm{PCa}$ & CTC analysis \\
\hline AR & $\begin{array}{l}\text { Opposing data: elevation of AR expression } \\
\text { and AR signaling in prostate tumors } \\
\text { promotes PCa metastasis by induction of } \\
\text { EMT [39]; other data suggest AR reverses } \\
\text { EMT and ADT can induce EMT }[40,41]\end{array}$ & $\begin{array}{l}\text { Cell proliferation and tumor } \\
\text { progression }[42,43]\end{array}$ & $\begin{array}{l}\text { Different AR expression patterns, } \\
\text { amplification, mutation, and variant } \\
\text { expression in PCa CTC [44-47] }\end{array}$ \\
\hline AKT & $\begin{array}{l}\text { PI3K-AKT directly or in crosstalk with } \\
\text { other signaling pathways can induce EMT } \\
\text { [48, 49]. Drugs inhibiting EMT via the } \\
\text { Akt/GSK-3 } \beta / \text { Snail pathway decrease the } \\
\text { invasiveness of PCa cells [50] }\end{array}$ & $\begin{array}{l}\text { Implicated in PCa cell proliferation } \\
\text { and resistance to apoptosis }[51,52]\end{array}$ & $\begin{array}{l}\text { Phosphorylated EGFR and PI3K/Akt } \\
\text { signaling kinases detected in breast cancer } \\
\text { patient CTCs [53], pERK/Akt pathway in } \\
\text { CTCs in hepatocellular carcinoma patients } \\
\text { [54], PTEN loss in circulating tumor cells } \\
\text { in CRPC patients [55]. No report in PCa } \\
\text { CTCs }\end{array}$ \\
\hline Hippo & $\begin{array}{l}\text { Deregulation of the Hippo pathway } \\
\text { contributes to EMT in colorectal cancer } \\
\text { [56], and FZD2 could promote clinically } \\
\text { relevant EMT in hepatocellular carcinoma } \\
\text { involving Hippo pathway [57] }\end{array}$ & $\begin{array}{c}\text { Emerging roles in PCa development, } \\
\text { progression, EMT, and mCRPC } \\
{[58,59]}\end{array}$ & $\begin{array}{l}\text { TAZ expression detected in NSCLC CTCs } \\
\text { [60], YAP association with metastasis in } \\
\text { human gastric cancer [61]. No report in } \\
\text { PCa CTCs }\end{array}$ \\
\hline MAPK & $\begin{array}{l}\text { MAPK mediates epithelial-mesenchymal } \\
\text { transition in cooperation with TGF- } \\
\beta / \text { Smad2 signaling and increased Snail and } \\
\text { Twist expression }[62-64]\end{array}$ & $\begin{array}{l}\text { Linked to proliferation, early } \\
\text { relapse, and development of } \\
\text { mCRPC }[65,66]\end{array}$ & $\begin{array}{l}\text { MAPK gene expression signature shown in } \\
\text { pancreatic CTCs [67], detection of mutant } \\
\text { RAS and RAF in CRC and in melanoma } \\
\text { CTCs }[68,69] \text {. No report in PCa CTCs }\end{array}$ \\
\hline$N F-\kappa B$ & $\begin{array}{c}\text { Hypoxia or overexpression of HIF- } 1 \alpha \\
\text { induces the EMT via NF- } \kappa \text { B in pancreatic } \\
\text { cancer cells [70] and inhibition of NF- } \kappa \text { B } \\
\text { deregulates EMT [71] }\end{array}$ & $\begin{array}{l}\text { Promotes PCa cell survival, tumor } \\
\text { invasion, metastasis, and } \\
\text { chemoresistance }[72,73]\end{array}$ & $\begin{array}{c}\text { NSCLC-CTC gene expression profile was } \\
\text { associated with cellular movement, cell } \\
\text { adhesion and differentiation, and cell-to- } \\
\text { cell signaling linked to PI3K/AKT, ERK1/2, } \\
\text { and NF- } \kappa \beta \text { pathways [74]. No report in } \\
\text { PCa CTCs }\end{array}$ \\
\hline $\begin{array}{l}\text { JAK/ } \\
\text { STAT }\end{array}$ & $\begin{array}{l}\text { IFN- } \gamma \text { can induce epithelial-to- } \\
\text { mesenchymal transition (EMT) in PCa } \\
\text { cells via the JAK-STAT signaling pathway } \\
\text { [75], and STAT3 may directly mediate } \\
\text { EMT progression and regulate ZEB1 } \\
\text { expression in CRC [76] }\end{array}$ & $\begin{array}{l}\text { PCa progression, cell proliferation, } \\
\text { and inhibition of apoptosis }[51,52]\end{array}$ & $\begin{array}{l}\text { No direct analysis of these pathways in } \\
\text { CTCs }\end{array}$ \\
\hline $\begin{array}{l}\text { Wnt/ } \\
\beta \text {-catenin }\end{array}$ & $\begin{array}{l}\text { Dysregulation of Wnt/ } \beta \text {-catenin signaling } \\
\text { has been implicated in the development of } \\
\text { cancer in different tissues such as lung, } \\
\text { skin, liver, and prostate [52], via regulating } \\
\text { Zeb1 in CRC [77] }\end{array}$ & $\begin{array}{l}\text { Wnt/ } \beta \text {-catenin pathway promotes } \\
\text { the metastatic spread of prostate } \\
\text { cancer cells by inducing EMT }[78]\end{array}$ & $\begin{array}{l}\text { Epithelial type CTCs and activation of } \\
\text { Wnt/ } \beta \text {-catenin signaling in lung cancer } \\
\text { cells [79]. No report in PCa CTCs }\end{array}$ \\
\hline Notch & $\begin{array}{c}\text { Crosstalk between the Jagged } 1 / \text { Notch and } \\
\text { JAK/STAT3 signaling pathways by } \\
\text { promoting EMT through Jagged-1 in } \\
\text { ovarian cancer [80] }\end{array}$ & $\begin{array}{l}\text { Notch signaling results in prostate } \\
\text { tumor recurrence via EMT [81] }\end{array}$ & $\begin{array}{l}\text { Increased production of ROS results in the } \\
\text { upregulation of Notch1 in CTCs in } \\
\text { metastatic breast and melanoma cancer } \\
\text { [82]. No report in PCa CTCs }\end{array}$ \\
\hline
\end{tabular}

TABLE 2: EMT markers detected in PCa tissue.

\begin{tabular}{lc}
\hline Epithelial markers & Mesenchymal markers \\
\hline E-cadherin [84] & Snail, Cat L [83] \\
Cytokeratin [85] & Vimentin, N-cadherin [84] \\
E-cadherin [88] & Vimentin [85] \\
E-cadherin, cytokeratin [89] & Twist [86, 87] \\
\hline
\end{tabular}

loss of E-cadherin reduced metastatic potential in invasive ductal carcinomas [92], suggesting that E-cadherin plays opposing roles in tumor progression by suppressing cancer cell invasion while promoting metastasis. Nonetheless, on balance, the data suggest that EMT markers may have predictive value with respect to recurrence and overall survival both in tissues and in CTCs [84]. Different studies show that E-cadherin suppresses invasion and metastasis. However, in a recent study, it has been shown that loss of E-cadherin reduced metastatic potential in invasive ductal carcinomas [92].

\section{AR, ADT, EMT, and Drug Resistance}

The AR, located on the X chromosome (Figure 2(a)), is a hormone-dependent transcription factor [93]. In the unstimulated state, the receptor is cytoplasmic and bound by heat-shock proteins [94]. When its ligand, dihydrotestosterone (DHT) or testosterone, binds via the AR ligand-binding domain (LBD) (Figure 2(a)), a structural change results in the detachment of AR from the heat-shock protein 90 (HSP90) complex, homodimerization of the receptor, and nuclear translocation. 


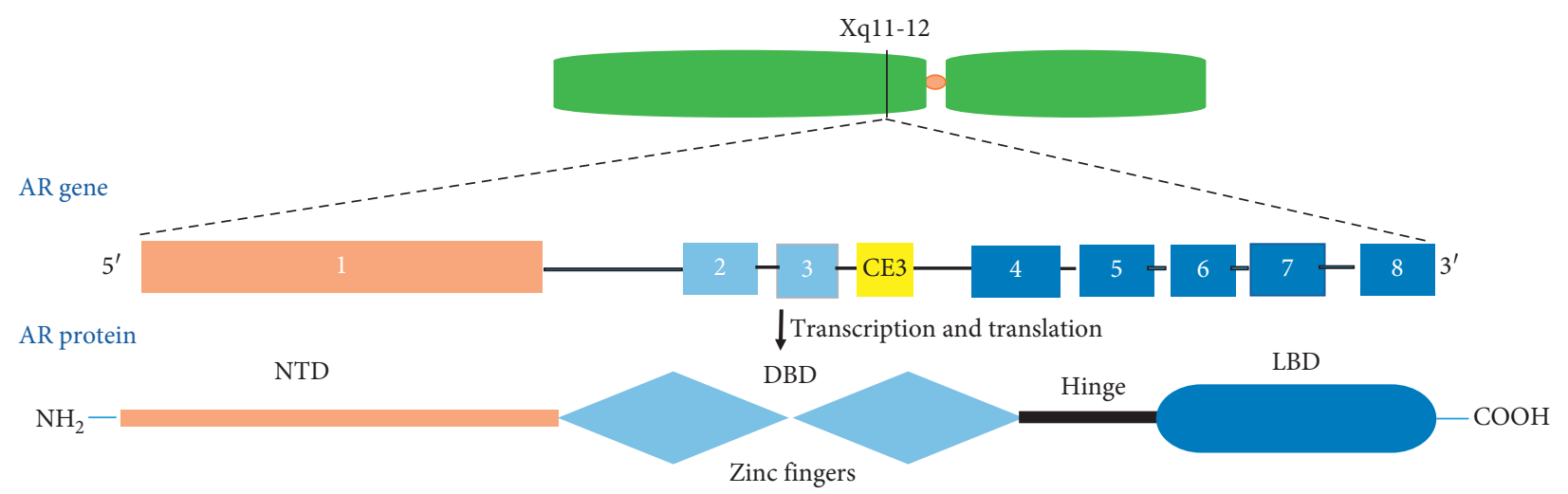

(a)

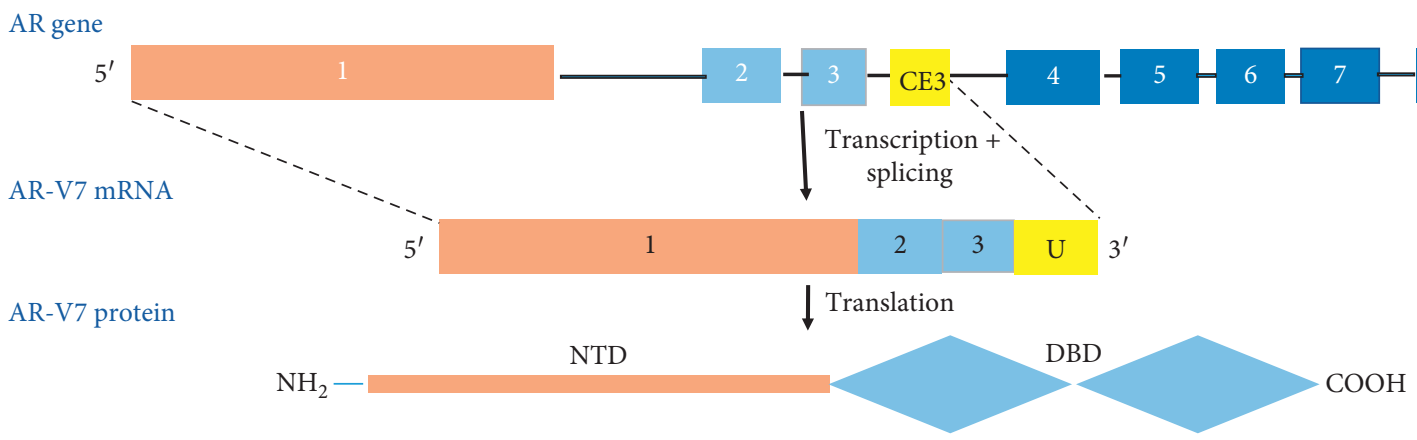

(b)

FIGURE 2: AR and AR-V7 gene and protein. The schematic indicates (a) the structural organisation of the AR gene and protein (NTD: amino terminal domain; DBD: DNA-binding domain; LBD: ligand-binding domain). (b) The transcription and translation of the AR-V7 protein including the exon/intron composition of the AR, highlighting the cryptic exon CE3 (middle) and domains of the AR retained in the AR-V7 protein (bottom).

In the nucleus, $\mathrm{AR}$ acts as a transcription factor by binding to androgen-response elements (AREs) in the promoter region of androgen-regulated genes $[95,96]$. AR transactivates genes which are responsible for cell growth, differentiation, and cell survival [97]. Consequently, increased AR signaling can potentially transform normal prostate cells into malignant PCa cells. Moreover, it has been shown that ADT therapy can select for cancer cells with further increased AR activity, for example, due to AR gene amplification [98].

The expression of alternative AR splice variants has been proposed as a mechanism underlying resistance to ADT $[99,100]$. Most splice variants result in the translation of a truncated AR protein lacking a functional C-terminal LBD but containing a functional transactivating $\mathrm{N}$-terminal domain. Without being capable of binding ligand, the resulting proteins are constitutively active as transcription factors and able to promote expression of certain target genes [97, 101]. At least 20 splice variants of AR have been identified in human prostate tissue and have been implicated in the development of mCRPC [101-104]. Amongst AR variants, ARV7 is highly expressed in MCRPC and is the most frequently disease-associated variant identified in the clinic $[105,106]$. The AR-V7 transcript results from alternative splicing of the AR gene such that the transcript contains exons 1,2 , and 3 together with a cryptic exon $3 \mathrm{E}$ (CE3) resulting in a truncated transcript $(\mathrm{U})$, resulting in premature transcriptional termination (Figure 2(b)). AR-V7 is constitutively active irrespective of androgen binding, which is a proposed mechanism of escape from ADT $[107,108]$.

There is no clear consensus with respect to the role of androgen signaling in the regulation of EMT. An early study using cell lines showed that androgen stimulation promoted EMT in both $\mathrm{LNCaP}$ and PC-3 cells but that there was an inverse relationship between $\mathrm{AR}$ receptor levels and androgen-mediated EMT marker expression and EMT-associated cytoskeletal changes. Low levels of AR induced by shRNA promoted PCa cell metastatic ability by inducing EMT while high levels did not [109]. In contrast, a recent study has shown that AR mRNA and protein expression is higher in metastatic tumor tissues than in primary tumors and increases with tumor stage and Gleason score. Patients with higher AR expression showed shorter recurrence-free survival, indicating a positive association between AR expression and tumor progression. Further, knockdown of AR using siRNA in C4-2B cells suppressed functional markers of EMT, viz cell migration and invasion, and mesenchymal marker proteins associated with EMT, while increasing the epithelial marker E-cadherin. These effects were recapitulated by treatment with the antiandrogen bicalutamide [39]. Thus, it appears that AR stimulation induces or suppresses EMT in cell culture in a cell-type-dependent fashion.

Studies with both normal mouse prostate and human prostate tumor models in mice have shown that androgen 
deprivation through surgical castration, while suppressing tumor growth, induces mesenchymal markers of EMT and markers of a stem cell phenotype, while suppressing epithelial markers. These changes were also seen in tissues of patients treated with ADT [110], supporting the view that AR signaling suppresses EMT, while ADT promotes it.

In further support of this view, ADT with enzalutamide in C4-2 cells, but not in PC-3 cells, induced EMT markers in a Snail-dependent fashion. Induction of EMT required both suppression of AR signaling and activation of Snail. Interestingly, Snail was downregulated by androgen in $\mathrm{AR}$ expressing C4-2 and VCaP cells but again, not in PC-3 cells. Importantly, the inverse correlation between $\mathrm{AR}$ signaling and Snail expression observed in C4-2 xenografts and castration-resistant patient-derived metastases in mice and in clinical samples supports the view that the induction of EMT is an adaptive response to ADT with enzalutamide [40]. ADT may favor acquisition of stem cell and EMT characteristics, expression of oncogenes, or suppression of tumor suppressor genes in AR-positive PCa cells, implying that $\mathrm{mCRPC}$ at least in part is achieved through EMT [41, 110-114].

Other data suggest that AR splice variants are involved in the development of drug resistance in PCa [105, 115-117]. One corollary of this hypothesis is that inhibition of the AR variants or their specific function might lead to reversal of EMT phenotype and that might in turn inhibit tumor spread $[41,118]$. Overall, however, this area remains understudied, and more data are needed to fully understand how the AR pathway and its manipulation during therapy may regulate EMT and thus potentially metastasis. Since mCRPC is ultimately the principal cause of death in many patients, the fundamental biological processes for the development and establishment of mCRPC need to be understood [119]. It is noteworthy that there is now mounting evidence in CTCs that the expression of EMT markers is associated with mCRPC $[120,121]$, highlighting the potential benefit in the analysis of CTCs to address the role of AR in metastasis and drug resistance.

\section{Akt Pathway in mCRPC}

As indicated above, due to the hormone-independent nature of mCRPC, it is unresponsive to all current forms of ADT. At this stage, AR expression may even be completely lost [122-124], raising the question as to how survival and proliferation of PCa cells occur at this stage. The main oncogenic signaling pathway implicated at this juncture is the PI3K/AKT-pathway, predominantly activated through frequent functional loss of the inhibitory tumor suppressor phosphatase and tensin homolog (PTEN), which is less common in localized PCa (20-30\%) but becomes more dominant and is found in up to $50-60 \%$ of mCRPCs. The result is uncontrolled, oncogenic Akt signaling (reviewed in $[125,126])$. The PI3K/AKT and AR pathways are highly networked with both positive and negative feedback loops [125], and in mCRPC, current literature indicates that negative feedback dominates. That is, inhibition of one pathway leads to reciprocal activation of the other [127-130].
Carver and colleagues have elucidated part of this interaction, demonstrating that the AR reduces AKT activation through the intermediary PHLPP, while AKT can transcriptionally downregulate AR output via HER kinase activity [127]. The exact role of PTEN in mediating this interaction is controversial. On the one hand, PTEN deletion has been associated with AKT activation and reduced AR levels [128, 131], and on the other hand, it may independently increase AR gene expression by removing transcriptional repression [130, 132-134]. Given the interconnected signaling network, outcomes of AR and AKT signaling or silencing may affect overall outcomes in a context-specific fashion, which is likely dependent on the presence and activity of other proteins that can affect the balance of feedback loops. For example, it has been shown that AR can transcriptionally repress PTEN expression in PCa cells while it increases PTEN expression in breast cancer cells and the report suggested this may be due to tissue-dependent availability of transcriptional cofactors [135]. Moreover, ADT may also affect the balance in these interconnected signaling pathways. Importantly, loss of PTEN has been associated with EMT driven through the AKT pathway or in cooperation with RAS signaling; thereby, lack of PTEN function could promote metastasis [136, 137].

\section{Hippo Signaling Pathway and Its Role in CRPC and EMT}

As indicated above, several signaling pathways may contribute to the induction of EMT and ultimately metastasis, with the AKT pathway of importance in the context of PCa. More recently, the YAP1 transcriptional coactivator regulated by the Hippo pathway has emerged as an important player in this scenario and in regulating PCa cell motility [138]. In the context of gastric cancer, PTEN inactivation has been proposed to link the Hippo and PI3K/Akt pathways to promote cancer development and tumorigenesis [139]. In normal tissue, the Hippo signaling pathway appears central to cell growth control and limits organ size by coordinating cell proliferation, growth, and death [140]. Different signals like cell polarity, cell-cell contact, extracellular matrix characteristics, and stress can result in the activation of the Hippo pathway (reviewed in [141]). Hippo signaling through a kinase cascade results in phosphorylation of oncogenic cotranscription factors known as YAP and TAZ, promoting their cytoplasmic retention and proteasomal degradation [142-144] (Figure 3).

Inactivation of the Hippo pathway allows for YAP and TAZ activation via dephosphorylation, which is required for translocation into the nucleus. Although TAZ and YAP lack intrinsic DNA-binding domains, they are recruited by and enhance the activity of other transcription factors at their target promoters $[145,146]$.

Hippo signaling can act as a tumor suppressor. Functional impairment of Hippo signaling is often due to the loss of MST1/2 or LATS1/2 function or due to YAP1 gene amplification. YAP1 is the most studied YAP isoform, and aberrant YAP1 activation is associated with the etiology of various malignancies including stomach [147], thyroid 


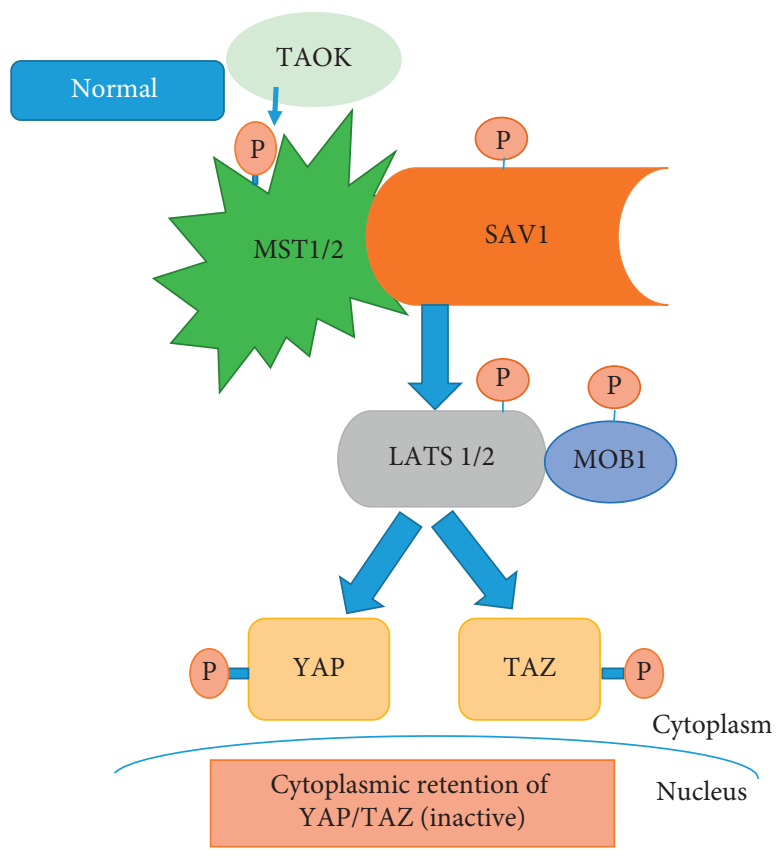

(a)

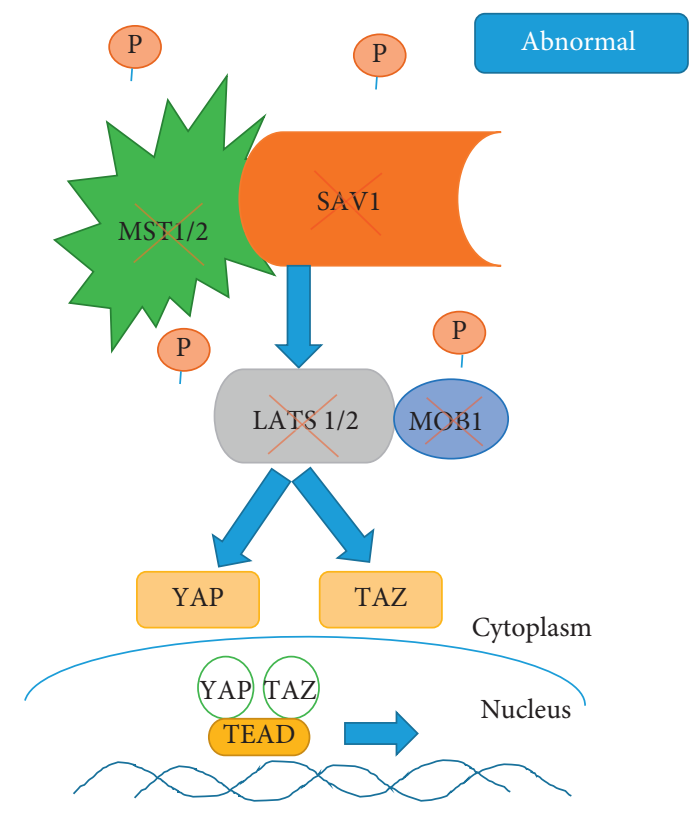

(b)

FIgURE 3: Hippo signaling pathway. Active Hippo signaling represses YAP and TAZ via phosphorylation (a), while inactive Hippo leads to dephosphorylation, nuclear translocation, and thus activation of TFs (b). The crossed out symbol indicates pathway members frequently lost in cancer.

[148], lung [149], colon [150], head and neck [151] ovarian [152], liver [153], and prostate cancer [154].

Most interestingly, YAP1 and AR directly interact in PCa cells. One study demonstrates that unlike in hormonesensitive prostate cancer cells, YAP1-AR interactions are androgen-insensitive and may cause resistance to enzalutamide in mCRPC cells. The WW/SH3 domain of YAP1 most likely facilitates the interaction with the AR amino terminal domain (NTD) [155].

One study proposes that increased nuclear YAP1, possibly due to the loss of Hippo signaling, may lead to increased complex formation between AR and YAP1 leading to androgen-independent binding of the complex to AREs in AR-driven promoters resulting in aberrant AR target gene expression possibly promoting $\mathrm{MCRPC}$ [58].

Importantly, YAP has been shown to promote metastasis through several mechanisms including EMT, and there is some evidence that the PTEN-AKT axis is involved in YAP1induced EMT $[145,156,157]$. The underlying mechanisms of EMT regulation by YAP are still emerging, but given the role of YAP as a transcriptional coregulator, it is not surprising that the pathways centrally involve EMT-TFs. Critically, YAP1 has been shown to network with the main EMT-TFs. For instance, high glucose-induced polyubiquitination of PTEN results in alteration of its phosphatase targets, including an increased focus on dephosphorylation and activation of EMT regulators such as Twist, Snail, and YAP1 [158]. YAP1 was also reported to drive EMT and likely NSCLC metastasis by TEAD-dependent transcriptional induction of SLUG [159]. Focusing on YAP's role in osteoblast differentiation, one study identified two links between YAP and Snail/Slug. In Snail/Slug-null skeletal stem/stromal cells, the levels of both YAP and TAZ were reduced via protein degradation due to activation of the Hippo pathway, while direct interaction of YAP with Snail and with Slug was shown to alter YAP/TEAD transcriptional activity [160]. Another study found that Twistinduced EMT in breast cancer cells is dependent on TAZ activity. The mechanism involved increased expression of the Hippo pathway inhibitors PAR-1 and PAR-3, which drive TAZ nuclear localisation. One would expect that YAP nuclear localisation may also be induced via PAR-1/-3 in this context, although this was not examined [161]. Another study revealed that increased extracellular matrix stiffness can induce EMT in breast cancer cells and that blocking $\beta 1$ integrin-mediated matrix stiffness prevented both Twist and YAP nuclear translocation albeit, interestingly, by different mechanisms [162].

In epithelial cells, cells are connected to each other by membrane structures called tight junctions, adherens junctions, and desmosomes. Any dysregulation in these junctions is implicated in metastasis and EMT $[163,164]$. Zona occludens- 1 (ZO-1) is a tight junction protein that is present in normal epithelial cells. Though not yet studied in $\mathrm{PCa}$, in melanoma, lung cancer cells, and breast cancer, ZO1 expression correlates with invasion properties of cancer cells [165-167]. One study found that YAP overexpression resulted in downregulation of ZO-1 and induced metastasis through EMT in NSCLC [159].

YAP (but not TAZ) has been shown to interact directly with ZEB1 and, remarkably, this interaction turns this transcriptional repressor into an activator. This is 
highlighted by the fact that ZEB1-mediated CDH1 (Ecadherin) repression is independent of YAP binding. Critically, gene upregulation by the ZEB1-YAP complex correlated with gene expression signatures of claudin-low breast cancer, a breast cancer subtype overall exhibiting an EMT phenotype. More importantly, ZEB1-YAP complexmediated gene expression was related to poor patient survival in hormone-independent breast cancers and linked to drug resistance and metastasis [168]. ZEB1 is known to repress several EMT-related miRNAs including miR375, which is associated with an epithelial phenotype. Nevertheless, miR375, a known YAP target, is commonly overexpressed in PCa and in fact has been indicated as a plasma marker of PCa. The suggested mechanism by which miR375 supports an epithelial phenotype is via feedback regulation, such that it targets and suppresses YAP transcript and thus YAP protein levels and thereby reversing EMT in PCa cells. Surprisingly however, high plasma miR375 level was associated with CTC positivity [169], suggesting that further investigations are needed to understand the complex network between YAP, ZEB1, miR375, EMT, and CTC formation. Additionally, hypoxia may, at least in part, induce EMT by stabilizing YAP and its nuclear translocation in $\mathrm{PCa}$ cell lines [170].

Not surprisingly, another study showed that inhibiting a key characteristic of epithelial tissue, namely, E-cadherinmediated cell-cell interaction, resulted in EMT and increased dissemination of Madin-Darby canine kidney cells. Interestingly, dissemination could be partially prevented by YAP knockdown. The same study found that not only is YAP required to allow nuclear entry of the MET initiating Wilms tumor protein 1 (WT1), but both WT1 and YAP form a complex at the $\mathrm{CDH} 1$ (E-cadherin) promoter and repress its transcription. These data, together with confirmation that E-cadherin inhibition upregulates YAP levels, indicate a double-negative feedback where E-cadherin and YAP mutually inhibit each other. This may be part of a switch between EMT and MET, thus potentially explaining the plasticity of the EMT process [171].

\section{YAP Crosstalk with AR AKT and AR Pathways}

Interestingly, one possible mechanism for PTEN loss of function is mediated by YAP. The pathway involves nuclear YAP-mediated activation of the TEAD family of transcription factors, leading to synthesis of the PTEN transcriptional repressor miRNA29c. Conversely, when YAP is inactivated via phosphorylation, PTEN levels are restored and the oncogenic function of YAP is inhibited [172]. Moreover, as mentioned above, PTEN ubiquitination can dephosphorylate and thus activate YAP causing its nuclear accumulation indicating a possible positive feedback regulation [158].

On the other hand, PTEN was identified as a negative regulator of AR activity such that the AR/PTEN interaction may mediate a tumor suppressor role for PTEN via suppression of AR and apoptosis induction in PCa cells [173]. However, as outlined above, the PTEN and AR network is still poorly understood, and data are conflicting. This is exemplified by another study with opposing findings, wherein PTEN deletion reduces both AR expression and AR transcriptional activity in $\mathrm{PCa}$ [131].

Taken together, emerging evidence indicates that YAP is part of the complex functional network that connects the AR and AKT pathways and thereby modulates $\mathrm{PCa}$ and mCRPC-at least in part-via EMT (Figure 4). However, more work is needed to better understand this interplay and its implications for the development of strategies to treat advanced PCa.

\section{Analysis of PCa CTCs to Explore the AR-AKT- YAP Connection and EMT}

The evaluation of molecular pathways underlying mCRPC is challenging because tissue biopsies are generally not available from late disease stages and animal models; further, although examination of tissue can provide some signaling pathway information, this mode of studying PCa has limitations. Liquid biopsies, and analysis of mCRPC CTCs, may be an alternative. While diagnostic CTC analysis in PCa is still in its infancy, there is ample evidence of its utility in this disease. Certainly, CTCs have been investigated by imaging and molecular technologies for expression of proteins, gene amplifications, mutations, and transcript expression on both targeted and comprehensive levels [174]. For PCa, increased CTC counts are associated with earlier disease progression and shorter OS, with enumeration of PCa CTCs using the CellSearch CTC platform gaining FDA approval as a prognostic indicator [175]. While common CTC isolation and analysis techniques favour epithelial CTCs, there have been numerous advances in improving capture, detection, and analysis of EMT-CTCs by screening for epithelial and mesenchymal marker expression [176-181]. Equally, as Table 1 shows, several major signaling pathways implicated in EMT have, to some extent, been analysed in CTC samples. In this review, we focussed on the AR, AKT, and Hippo pathways as being central to mCRPC, at least in part via EMT regulation. It is now important to consider how these pathways have been explored in CTCs, in order to gauge the potential for CTC analysis to advance our understanding of these pathways in mCRPC. Accordingly, we note that DNA-, RNA-, and protein-centric analyses for AR and AR-V7 levels in isolated CTCs have become a busy field of PCa research. Moreover, efforts are being made to translate CTC-based AR and AR-V7 detection into clinical settings aimed initially at stratifying patients to define either eligibility criteria or outcome markers for clinical trials (https://clinicaltrials.gov) [182].

mCRPC-associated AR amplification and mutation analysis have been performed in CTCs using hybridization techniques such as fluorescent in situ hybridization (FISH) and other molecular approaches. In general, these studies were able to validate the association of CTC-based AR amplification or mutation with $\mathrm{MCRPC}$, while the relevance of AR cellular localisation in CTCs was shown in mCRPC and in response to taxanes [46, 47, 183-186]. The presence of full-length AR and AR-V7 in CTCs has been studied 


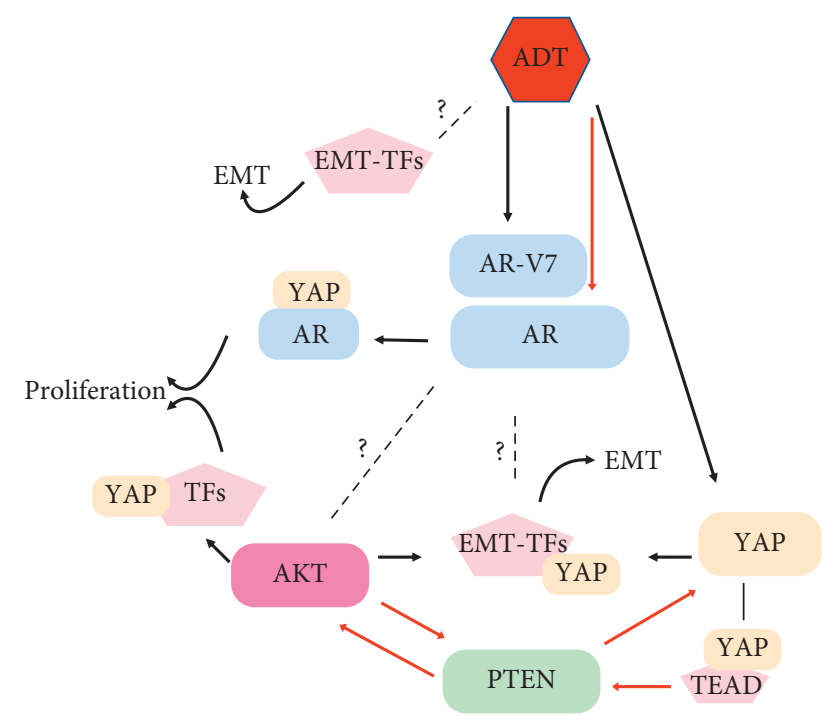

FIgURE 4: AR AKT and YAP interaction. Schematic presentation of reported and likely (dotted lines) network connections between $\mathrm{ADT}, \mathrm{AR}, \mathrm{AKT}$, and YAP.

extensively at the RNA level and CTC-based AR-V7 in particular was found to correlate with mCRPC and primary resistance to abiraterone and enzalutamide $[45,182,184$, $187,188]$. Interestingly, there have also been efforts at detecting both AR and AR-V7 as biomarkers in other liquid biopsy entities, including plasma-derived circulating tumor RNA (ctRNA), exosomes, or even in urine. We recently compared some of these strategies and found both fulllength $A R$ and V7 RNA detection is more sensitive and specific if performed on CTC samples, as compared to ctRNA or exosomes. We also demonstrated that AR-V7 is detectable from CTC-RNA up to $48 \mathrm{~h}$ post blood draw into common EDTA vacutubes $[189,190]$. With improved ARV7-specific antibody availability, CTC immunocytostaining more recently revealed that specific detection of AR-V7 in CTC nuclei is an even better predictor of OS and PFS in CRPC patients [191, 192]. In general, it appears nuclear AR is found in most CTCs positive for AR-V7 RNA, reflecting the predominant tendency for $\mathrm{AR}-\mathrm{V} 7$ to be nuclear localized in mCRPC tissue $[188,193]$. In CRPC patients, AR-V7-positive CTCs have been shown to correlate with enzalutamide and abiraterone resistance [187]. In any case, when investigating the interplay of AR/AR-V7 with other pathways, especially transcriptional coactivators, immunocytodetection in CTCs appears to be the most logical strategy.

Several studies have also analysed PTEN loss in CTCs, which, as outlined above, may allow oncogenic activation of the AKT pathway and is an important PCa biomarker. Loss of PTEN and gain of AR copy numbers were reported in PCa CTCs [194-197], while testing for activation of the AKT pathway has been performed for example by phosho-Akt or phospho-S6 kinase immunostaining in breast cancer and multiple myeloma CTCs [198].

Reports on hippo signaling and YAP1 analysis in CTCs, by contrast, are still scarce. One study assessed expression of TAZ using RNA in situ hybridization (RNAish) probing of
NSCLC CTCs. TAZ expression was detected more frequently in EGFR wild-type cancers while its expression in CTCs was associated with lymph node status of the disease [60]. It is likely that YAP1 could be analysed in a similar fashion in CTCs or preferentially using immunocytostaining, as the latter would also reveal cellular localisation and thus activity as well as colocalisation with other proteins. However, to our knowledge, direct detection of YAP1 in CTCs has not yet been reported, although the relationship of YAP1 to EMT suggests that activated YAP1 should correlate with increased formation of CTCs. Some indirect evidence lends further strength to this idea, as a recent report showed that the Rho GTPase activating protein 29 (ARHGAP29) is a transcriptional target of YAP1 in gastric cancer. High ARHGAP29 levels were shown to regulate cytoskeletal actin and cell migration. Importantly, the authors also demonstrated using a mouse model that CTCs exhibited increased ARHGAP29 RNA levels compared with primary tumor site cells $[61,199]$. Final proof of a YAP1-ARHGAP29 connection in CTCs remains pending, however. Another transcriptional target of YAP is miR375 which was associated with CTC positivity, yet a direct connection was again not shown in CTCs [169].

Taken together, the reviewed data suggest that AR-AKTYAP1 network can be analysed in CTCs. Since tumor tissue is rarely available in the mCRPC setting, and blood samples can be easily taken, future endeavours in CTC analysis could open the way to better understand ADT resistance and thereby inform the development of improved diagnostic, prognostic, and therapeutic capabilities.

Analysis of CTCs has provided a foundation for liquid biopsy, especially in the absence of biopsy tissue. However, there are serious challenges with CTC isolation, detection, and downstream analysis. One is that CTC numbers are relatively small within large populations of blood cells and the volume of blood that can be taken depends on the patient's general condition. CTCs are quite heterogeneous in terms of physical properties (size, elasticity, and surface charge), biological characteristics, and expression of different tumor markers making enrichment or isolation of all CTCs difficult (reviewed in [200]). In general, the low CTC numbers make downstream analysis of CTCs another challenge. Protein detection is usually limited to immunocytostaining which relies on antibody-based detection and the number of microscope channels available with 3 usually dedicated to detection of a CTC marker (often cytokeratin), a nuclear marker such as DAPI, and exclusion of a blood cell marker usually CD45. Nevertheless, some studies have detected additional proteins such as EMT markers $[21,22,176]$ or posttranslational modifications such as phosphorylation of pFAK, pPI3K, pSRC, pEGFR, and pAkt [53, 201-204].

\section{Conclusion}

Here, we reviewed connections between the AR pathway and the AKT and Hippo pathways, exploring a potential role for this signaling nexus in EMT and mCRPC. Though current literature supports the importance of this tripartite relationship, further study is now needed to better evaluate its 
importance in $\mathrm{PCa}$, as well as its clinical potential in defining biomarkers or drug targets. Analysis of PCa CTCs may facilitate deeper investigations into AR/AKT/Hippo pathway interactions, and how these drive EMT as well as ADT resistance. Such analyses may ultimately mediate the emergence of new diagnostic/prognostic assays directed towards $\mathrm{PCa}$, though at this time insufficient data are available to establish feasibility of this concept. Indeed, while some aspects of these pathways have already been investigated in CTCs, optimisation of more comprehensive CTC analysis methods is now needed to permit the dissection of these pathway interactions, as a precursor to this significant goal.

\section{Conflicts of Interest}

The authors declare that there are no conflicts of interest regarding the publication of this paper.

\section{Acknowledgments}

This work was funded by the Centre for Oncology Education \& Research Translation (CONCERT) through Cancer Institute NSW under grant number 13/TRC/1-01. TK is recipient of a Western Sydney University Androgen Receptor Research Scholarship.

\section{References}

[1] A. Jemal, F. Bray, M. M. Center, J. Ferlay, E. Ward, and D. Forman, "Global cancer statistics," CA: A Cancer Journal for Clinicians, vol. 61, no. 2, pp. 69-90, 2011.

[2] F. Bray, J. Ferlay, I. Soerjomataram, R. L. Siegel, L. A. Torre, and A. Jemal, "Global cancer statistics 2018: GLOBOCAN estimates of incidence and mortality worldwide for 36 cancers in 185 countries," CA: A Cancer Journal for Clinicians, vol. 68, no. 6, pp. 394-424, 2018.

[3] D. T. Hoang, K. A. Iczkowski, D. Kilari, W. See, and M. T. Nevalainen, "Androgen receptor-dependent and-independent mechanisms driving prostate cancer progression: opportunities for therapeutic targeting from multiple angles," Oncotarget, vol. 8, no. 2, p. 3724, 2017.

[4] D. Shapiro and B. Tareen, "Current and emerging treatments in the management of castration-resistant prostate cancer," Expert Review of Anticancer Therapy, vol. 12, no. 7, pp. 951-964, 2012.

[5] C. D. Chen, D. S. Welsbie, C. Tran et al., "Molecular determinants of resistance to antiandrogen therapy," Nature Medicine, vol. 10, no. 1, pp. 33-39, 2004.

[6] K. E. Knudsen and H. I. Scher, "Starving the addiction: new opportunities for durable suppression of AR signaling in prostate cancer," Clinical Cancer Research, vol. 15, no. 15, pp. 4792-4798, 2009.

[7] D. L. Longo, "New therapies for castration-resistant prostate cancer," New England Journal of Medicine, vol. 363, no. 5, pp. 479-481, 2010.

[8] J. S. De Bono, C. J Logothetis, A Molina et al., "Abiraterone and increased survival in metastatic prostate cancer," The New England Journal of Medicine, vol. 364, no. 364, pp. 1995-2005, 2011.

[9] C. J. Ryan, M. R Smith, J. S de Bono et al., "Abiraterone in metastatic prostate cancer without previous chemotherapy,"
The New England Journal of Medicine, vol. 368, no. 368, pp. 138-148, 2013.

[10] T. M. Beer, A. J. Armstrong, D. E. Rathkopf et al., "Enzalutamide in metastatic prostate cancer before chemotherapy," New England Journal of Medicine, vol. 371, no. 5, pp. 424-433, 2014.

[11] H. I. Scher, K. Fizazi, F. Saad et al., "Increased survival with enzalutamide in prostate cancer after chemotherapy," New England Journal of Medicine, vol. 367, no. 13, pp. 1187-1197, 2012.

[12] K. Fizazi, H. I. Scher, A. Molina et al., "Abiraterone acetate for treatment of metastatic castration-resistant prostate cancer: final overall survival analysis of the COU-AA-301 randomised, double-blind, placebo-controlled phase 3 study," The Lancet Oncology, vol. 13, no. 10, pp. 983-992, 2012.

[13] M. Fang, M. Nakazawa, E. S. Antonarakis, and C. Li, "Efficacy of abiraterone and enzalutamide in pre-and postdocetaxel castration-resistant prostate cancer: a trial-level meta-analysis," Prostate Cancer, vol. 2017, Article ID 8560827, 8 pages, 2017.

[14] S. Linder, H. G. van der Poel, A. M. Bergman, W. Zwart, and S. Prekovic, "Enzalutamide therapy for advanced prostate cancer: efficacy, resistance and beyond," Endocrine-Related Cancer, vol. 26, no. 1, pp. R31-R52, 2018.

[15] V. Mittal, "Epithelial mesenchymal transition in tumor metastasis," Annual Review of Pathology: Mechanisms of Disease, vol. 13, no. 1, pp. 395-412, 2018.

[16] M. A. Nieto, R. Y.-J. Huang, R. A. Jackson, and J. P. Thiery, "EMT: 2016," Cell, vol. 166, no. 1, pp. 21-45, 2016.

[17] D. Yao, C. Dai, and S. Peng, "Mechanism of the mesenchymal-epithelial transition and its relationship with metastatic tumor formation," Molecular Cancer Research, vol. 9, no. 12, pp. 1608-1620, 2011.

[18] N. J. Caixeiro, N. Kienzle, S. H. Lim et al., "Circulating tumour cells-a bona fide cause of metastatic cancer," Cancer and Metastasis Reviews, vol. 33, no. 2-3, pp. 747-756, 2014.

[19] N. Stylianou, M. L. Lehman, C. Wang et al., "A molecular portrait of epithelial-mesenchymal plasticity in prostate cancer associated with clinical outcome," Oncogene, vol. 38, no. 7, pp. 913-934, 2019.

[20] M. Cheng, L. Liu, H.-S. Yang, and G.-F. Liu, "Circulating tumor cells are associated with bone metastasis of lung cancer," Asian Pacific Journal of Cancer Prevention, vol. 15, no. 15, pp. 6369-6374, 2014.

[21] Y.-J. Yang, Y.-Y. Kong, G.-X. Li, Y. Wang, D.-W. Ye, and B. Dai, "Phenotypes of circulating tumour cells predict time to castration resistance in metastatic castration-sensitive prostate cancer," BJU International, vol. 124, no. 2, pp. 258-267, 2019.

[22] J. Chen, S. Cao, B. Situ et al., "Metabolic reprogrammingbased characterization of circulating tumor cells in prostate cancer," Journal of Experimental \& Clinical Cancer Research, vol. 37, no. 1, p. 127, 2018.

[23] P. S. Steeg, "Tumor metastasis: mechanistic insights and clinical challenges," Nature Medicine, vol. 12, no. 8, pp. 895-904, 2006.

[24] M. Montanari, S. Rossetti, C. Cavaliere et al., "Epithelialmesenchymal transition in prostate cancer: an overview," Oncotarget, vol. 8, no. 21, p. 35376, 2017.

[25] U.-G. Lo, C.-F. Lee, M.-S. Lee, and J.-T. Hsieh, "The role and mechanism of epithelial-to-mesenchymal transition in 
prostate cancer progression," International Journal of Molecular Sciences, vol. 18, no. 10, p. 2079, 2017.

[26] M. P. Stemmler, R. L. Eccles, S. Brabletz, and T. Brabletz, "Non-redundant functions of EMT transcription factors," Nature Cell Biology, vol. 21, no. 1, pp. 102-112, 2019.

[27] P. G. Santamaría, G. Moreno-Bueno, and A. Cano, "Contribution of epithelial plasticity to therapy resistance," Journal of Clinical Medicine, vol. 8, no. 5, p. 676, 2019.

[28] M.-H. Yang, M.-Z. Wu, S.-H. Chiou et al., "Direct regulation of TWIST by HIF- $1 \alpha$ promotes metastasis," Nature Cell Biology, vol. 10, no. 3, pp. 295-305, 2008.

[29] T. Imai, A. Horiuchi, C. Wang et al., "Hypoxia attenuates the expression of E-cadherin via up-regulation of SNAIL in ovarian carcinoma cells," The American Journal of Pathology, vol. 163, no. 4, pp. 1437-1447, 2003.

[30] J. Yang and R. A. Weinberg, "Epithelial-mesenchymal transition: at the crossroads of development and tumor metastasis," Developmental Cell, vol. 14, no. 6, pp. 818-829, 2008.

[31] Y. Katoh and M. Katoh, "Hedgehog signaling, epithelial-tomesenchymal transition and miRNA," International Journal of Molecular Medicine, vol. 22, no. 3, pp. 271-275, 2008.

[32] B. D. Craene and G. Berx, "Regulatory networks defining EMT during cancer initiation and progression," Nature Reviews Cancer, vol. 13, no. 2, pp. 97-110, 2013.

[33] M. A. Huber, H. Beug, and T. Wirth, "Epithelial-mesenchymal transition: NF- $\kappa \mathrm{B}$ takes center stage," Cell Cycle, vol. 3, no. 12, pp. 1477-1480, 2004.

[34] A. Moustakas and C.-H. Heldin, "Signaling networks guiding epithelial-mesenchymal transitions during embryogenesis and cancer progression," Cancer Science, vol. 98, no. 10, pp. 1512-1520, 2007.

[35] G. Christofori, "New signals from the invasive front," $\mathrm{Na}$ ture, vol. 441, no. 7092, pp. 444-450, 2006.

[36] J. P. Thiery, "Epithelial-mesenchymal transitions in tumour progression," Nature Reviews Cancer, vol. 2, no. 6, pp. 442-454, 2002.

[37] J. P. Thiery, H. Acloque, R. Y. J. Huang, and M. A. Nieto, "Epithelial-mesenchymal transitions in development and disease," Cell, vol. 139, no. 5, pp. 871-890, 2009.

[38] R. Kalluri and R. A. Weinberg, "The basics of epithelialmesenchymal transition," Journal of Clinical Investigation, vol. 119, no. 6, pp. 1420-1428, 2009.

[39] C.-Y. Lin, Y.-J. Jan, L.-K. Kuo et al., "Elevation of androgen receptor promotes prostate cancer metastasis by induction of epithelial-mesenchymal transition and reduction of KAT5," Cancer Science, vol. 109, no. 11, pp. 3564-3574, 2018.

[40] L. Miao, L. Yang, R. Li et al., "Disrupting androgen receptor signaling induces snail-mediated epithelial-mesenchymal plasticity in prostate cancer," Cancer Research, vol. 77, no. 11, pp. 3101-3112, 2017.

[41] D. Kong, S. Sethi, Y. Li et al., "Androgen receptor splice variants contribute to prostate cancer aggressiveness through induction of EMT and expression of stem cell marker genes," The Prostate, vol. 75, no. 2, pp. 161-174, 2015.

[42] D. N. Lavery and C. L. Bevan, "Androgen receptor signalling in prostate cancer: the functional consequences of acetylation," BioMed Research International, vol. 2011, Article ID 862125, 7 pages, 2010.

[43] M. E. Tan, J. Li, H. E. Xu, K. Melcher, and E.-l. Yong, "Androgen receptor: structure, role in prostate cancer and drug discovery," Acta Pharmacologica Sinica, vol. 36, no. 1, pp. 3-23, 2015.
[44] I. Puche-Sanz, M. J. Alvarez-Cubero, M. Pascual-Geler et al., "A comprehensive study of circulating tumour cells at the moment of prostate cancer diagnosis: biological and clinical implications of EGFR, AR and SNPs," Oncotarget, vol. 8, no. 41, pp. 70472-70480, 2017.

[45] Y. Ma, A. Luk, F. Young et al., "Droplet digital PCR based androgen receptor variant 7 (AR-V7) detection from prostate cancer patient blood biopsies," International Journal of Molecular Sciences, vol. 17, no. 8, p. 1264, 2016.

[46] J. Podolak, K. Eilers, T. Newby et al., "Androgen receptor amplification is concordant between circulating tumor cells and biopsies from men undergoing treatment for metastatic castration resistant prostate cancer," Oncotarget, vol. 8, no. 42, p. 71447, 2017.

[47] Y. Jiang, J. F. Palma, D. B. Agus, Y. Wang, and M. E. Gross, "Detection of androgen receptor mutations in circulating tumor cells in castration-resistant prostate cancer," Clinical Chemistry, vol. 56, no. 9, pp. 1492-1495, 2010.

[48] W. Xu, Z. Yang, and N. Lu, "A new role for the PI3K/Akt signaling pathway in the epithelial-mesenchymal transition," Cell Adhesion \& Migration, vol. 9, no. 4, pp. 317-324, 2015.

[49] J. Dong, B. Zhai, W. Sun, F. Hu, H. Cheng, and J. Xu, "Activation of phosphatidylinositol 3-kinase/AKT/snail signaling pathway contributes to epithelial-mesenchymal transition-induced multi-drug resistance to sorafenib in hepatocellular carcinoma cells," PLoS One, vol. 12, no. 9, Article ID e0185088, 2017.

[50] F. Fang, S. Chen, J. Ma et al., "Juglone suppresses epithelialmesenchymal transition in prostate cancer cells via the protein kinase $\mathrm{B} /$ glycogen synthase kinase- $3 \beta /$ Snail signaling pathway," Oncology Letters, vol. 16, no. 2, pp. 2579-2584, 2018.

[51] S. Sittadjody, T. Thangasamy, B. NickKolgh, and K. C. Balaji, "Non-androgen signaling pathways in castration-resistant prostate cancer," in Managing Metastatic Prostate Cancer in Your Urological Oncology Practice, pp. 35-63, Springer, Berlin, Germany, 2016.

[52] H. B. da Silva, E. P. Amaral, E. L. Nolasco et al., "Dissecting major signaling pathways throughout the development of prostate cancer," Prostate Cancer, vol. 2013, Article ID 920612, 23 pages, 2013.

[53] G. Kallergi, S. Agelaki, A. Kalykaki, C. Stournaras, D. Mavroudis, and V. Georgoulias, "Phosphorylated EGFR and PI3K/Akt signaling kinases are expressed in circulating tumor cells of breast cancer patients," Breast Cancer Research, vol. 10, no. 5, p. R80, 2008.

[54] J. Li, L. Shi, X. Zhang et al., "pERK/pAkt phenotyping in circulating tumor cells as a biomarker for sorafenib efficacy in patients with advanced hepatocellular carcinoma," Oncotarget, vol. 7, no. 3, p. 2646, 2016.

[55] E. A. Punnoose, R. Ferraldeschi, E. Szafer-Glusman et al., "PTEN loss in circulating tumour cells correlates with PTEN loss in fresh tumour tissue from castration-resistant prostate cancer patients," British Journal Of Cancer, vol. 113, no. 8, pp. 1225-1233, 2015.

[56] D. D. Shao, W. Xue, E. B. Krall et al., "KRAS and YAP1 converge to regulate EMT and tumor survival," Cell, vol. 158, no. 1, pp. 171-184, 2014.

[57] H. Ou, Z. Chen, L. Xiang et al., "Frizzled 2-induced epithelial-mesenchymal transition correlates with vasculogenic mimicry, stemness, and Hippo signaling in hepatocellular carcinoma," Cancer Science, vol. 110, no. 4, pp. 1169-1182, 2019. 
[58] L. Zhang, S. Yang, X. Chen et al., "The hippo pathway effector YAP regulates motility, invasion, and castration-resistant growth of prostate cancer cells," Molecular and Cellular Biology, vol. 35, no. 8, pp. 1350-1362, 2015.

[59] O. Salem and C. G. Hansen, "The hippo pathway in prostate cancer," Cells, vol. 8, no. 4, p. 370, 2019.

[60] M. Wu, Y. Wang, H. Wu, and K. Cai, "TAZ expression in three distinct circulating tumor cells of NSCLC patients," International Journal of Clinical and Experimental Pathology, vol. 10, no. 5, pp. 5721-5729, 2017.

[61] Y. Qiao, J. Chen, Y. B. Lim et al., "YAP regulates actin dynamics through ARHGAP29 and promotes metastasis," Cell Reports, vol. 19, no. 8, pp. 1495-1502, 2017.

[62] M. Huang, Y.-P. Wang, L.-Q. Zhu, Q. Cai, H.-H. Li, and H.-F. Yang, "MAPK pathway mediates epithelial-mesenchymal transition induced by paraquat in alveolar epithelial cells," Environmental Toxicology, vol. 31, no. 11, pp. 1407-1414, 2016.

[63] O. Hawsawi, V. Henderson, L. J. Burton, J. Dougan, P. Nagappan, and V. Odero-Marah, "High mobility group A2 (HMGA2) promotes EMT via MAPK pathway in prostate cancer," Biochemical and Biophysical Research Communications, vol. 504, no. 1, pp. 196-202, 2018.

[64] T. Gui, Y. Sun, A. Shimokado, and Y. Muragaki, "The roles of mitogen-activated protein kinase pathways in TGF-betainduced epithelial-mesenchymal transition," Journal of Signal Transduction, vol. 2012, Article ID 289243, 10 pages, 2012.

[65] R. Mukherjee, D. H. McGuinness, P. McCall et al., "Upregulation of MAPK pathway is associated with survival in castrate-resistant prostate cancer," British Journal of Cancer, vol. 104, no. 12, pp. 1920-1928, 2011.

[66] G. Rodríguez-Berriguete, B. Fraile, P. Martínez-Onsurbe, G. Olmedilla, R. Paniagua, and M. Royuel, "MAP kinases and prostate cancer," Journal of Signal Transduction, vol. 2012, Article ID 169170, 9 pages, 2012.

[67] G. Sergeant, R. V. Eijsden, T. Roskams, V. Van Duppen, and B. Topal, "Pancreatic cancer circulating tumour cells express a cell motility gene signature that predicts survival after surgery," BMC Cancer, vol. 12, no. 1, p. 527, 2012.

[68] J. M. Loree, S. Kopetz, and K. P. S. Raghav, "Current companion diagnostics in advanced colorectal cancer; getting a bigger and better piece of the pie," Journal of Gastrointestinal Oncology, vol. 8, no. 1, pp. 199-212, 2017.

[69] A. L. Reid, J. B. Freeman, M. Millward, M. Ziman, and E. S. Gray, "Detection of BRAF-V600E and V600K in melanoma circulating tumour cells by droplet digital PCR," Clinical Biochemistry, vol. 48, no. 15, pp. 999-1002, 2015.

[70] Z.-X. Cheng, B. Sun, S. Wang et al., "Nuclear factor$\kappa \mathrm{b}$-dependent epithelial to mesenchymal transition induced by HIF- $1 \alpha$ activation in pancreatic cancer cells under hypoxic conditions," PLoS One, vol. 6, no. 8, Article ID e23752, 2011.

[71] A. Nomura, K. Majumder, B. Giri et al., "Inhibition of NF- $\kappa$ B pathway leads to deregulation of epithelial-mesenchymal transition and neural invasion in pancreatic cancer," Laboratory Investigation, vol. 96, no. 12, pp. 1268-1278, 2016.

[72] D. Verzella, M. Fischietti, D. Capece et al., "Targeting the NF- $\kappa$ B pathway in prostate cancer: a promising therapeutic approach?," Current Drug Targets, vol. 17, no. 3, pp. 311-320, 2016.

[73] J. Staal and R. Beyaert, "Inflammation and NF- $\kappa$ B signaling in prostate cancer: mechanisms and clinical implications," Cells, vol. 7, no. 9, p. 122, 2018.
[74] J. Mariscal, M. Alonso-Nocelo, L. Muinelo-Romay et al., "Molecular profiling of circulating tumour cells identifies Notch1 as a principal regulator in advanced non-small cell lung cancer," Scientific Reports, vol. 6, p. 37820, 2016.

[75] U.-G. Lo, R. Pong, D. Yang et al., "Ifn $\gamma$-induced IFIT5 promotes epithelial-to-mesenchymal transition in prostate cancer via miRNA processing," Cancer Research, vol. 79, no. 6, pp. 1098-1112, 2018.

[76] H. Xiong, J. Hong, W. Du et al., "Roles of STAT3 and ZEB1 proteins in E-cadherin down-regulation and human colorectal cancer epithelial-mesenchymal transition," Journal of Biological Chemistry, vol. 287, no. 8, pp. 5819-5832, 2012.

[77] M. Zhang, F. Miao, R. Huang et al., "RHBDD1 promotes colorectal cancer metastasis through the Wnt signaling pathway and its downstream target ZEB1," Journal of Experimental \& Clinical Cancer Research, vol. 37, no. 1, p. 22, 2018.

[78] M.-S. Lee, J. Lee, Y. M. Kim, and H. Lee, "The metastasis suppressor CD82/KAI1 represses the TGF- $\beta 1$ and Wnt signalings inducing epithelial-to-mesenchymal transition linked to invasiveness of prostate cancer cells," The Prostate, vol. 79, no. 12, pp. 1394-1405, 2019.

[79] C.-J. Chen, C.-J. Yang, M.-S. Huang, and Y.-P. Liu, "Epithelial-type CD133+ stem-like lung cancer cells emerge higher drug resistance through MDFIC-mediated Wnt/ $\beta$-catenin signaling pathway," in Proceedings of the AACR Annual Meeting 2017, Washington, DC, USA, April 2017.

[80] J. Yang, H. Xing, D. Lu et al., "Role of Jagged1/STAT 3 signalling in platinum-resistant ovarian cancer," Journal of Cellular and Molecular Medicine, vol. 23, no. 6, pp. 40054018, 2019.

[81] M. Orzechowska, D. Jedroszka, R. Hamouz, and A. K. Bednarek, PO-151 Notch Signalling Differentiates Disease-free Survival in Prostate Cancer Patients by Affecting the Epithelial-To-Mesenchymal Transition-Associated Processes, BMJ Publishing Group Limited, London, UK, 2018.

[82] M. L. Sprouse, T. Welte, D. Boral et al., "PMN-MDSCs enhance CTC metastatic properties through reciprocal interactions via ROS/Notch/Nodal signaling," International Journal of Molecular Sciences, vol. 20, no. 8, p. 1916, 2019.

[83] L. J. Burton, O. Hawsawi, Q. Loyd et al., "Association of Epithelial Mesenchymal Transition with prostate and breast health disparities," PLoS One, vol. 13, no. 9, Article ID e0203855, 2018.

[84] S. Figiel, C. Vasseur, F. Bruyere, F. Rozet, K. Maheo, and G. Fromont, "Clinical significance of epithelial-mesenchymal transition markers in prostate cancer," Human $\mathrm{Pa}$ thology, vol. 61, pp. 26-32, 2017.

[85] K. A. Cheaito, H. F. Bahmad, O. Hadadeh et al., "EMT markers in locally-advanced prostate cancer: predicting recurrence?," Frontiers in Oncology, vol. 9, p. 131, 2019.

[86] P. Lyu, S.-D. Zhang, H.-F. Yuen et al., "Identification of TWIST-interacting genes in prostate cancer," Science China Life Sciences, vol. 60, no. 4, pp. 386-396, 2017.

[87] A. E. Abdelrahman, S. A. Arafa, and R. A. Ahmed, "Prognostic value of twist-1, E-cadherin and EZH2 in prostate cancer: an immunohistochemical study," Turkish Journal of Pathology, vol. 1, no. 1, pp. 198-210, 2017.

[88] K. Gravdal, O. J. Halvorsen, S. A. Haukaas, and L. A. Akslen, "A switch from E-cadherin to N-cadherin expression indicates epithelial to mesenchymal transition and is of strong and independent importance for the progress of prostate cancer," Clinical Cancer Research, vol. 13, no. 23, pp. 7003-7011, 2007. 
[89] P. Alonso-Magdalena, C. Brössner, A. Reiner et al., "A role for epithelial-mesenchymal transition in the etiology of benign prostatic hyperplasia," Proceedings of the National Academy of Sciences, vol. 106, no. 8, pp. 2859-2863, 2009.

[90] H. M. Behnsawy, H. Miyake, K.-I. Harada, and M. Fujisawa, "Expression patterns of epithelial-mesenchymal transition markers in localized prostate cancer: significance in clinicopathological outcomes following radical prostatectomy," BJU International, vol. 111, no. 1, pp. 30-37, 2013.

[91] H. Whiteland, S. Spencer-Harty, D. H. Thomas et al., "Putative prognostic epithelial-to-mesenchymal transition biomarkers for aggressive prostate cancer," Experimental and Molecular Pathology, vol. 95, no. 2, pp. 220-226, 2013.

[92] V. Padmanaban, I. Krol, Y. Suhail et al., "E-cadherin is required for metastasis in multiple models of breast cancer," Nature, vol. 573, no. 7774, pp. 439-444, 2019.

[93] I. U. Agoulnik, A. Vaid, M. Nakka et al., "Androgens modulate expression of transcription intermediary factor 2, an androgen receptor coactivator whose expression level correlates with early biochemical recurrence in prostate cancer," Cancer Research, vol. 66, no. 21, pp. 10594-10602, 2006.

[94] Y. Kim, S. Alarcon, S. Lee et al., "Update on Hsp90 inhibitors in clinical trial," Current Topics in Medicinal Chemistry, vol. 9, no. 15, pp. 1479-1492, 2009.

[95] A. A. Shafi, A. E. Yen, and N. L. Weigel, “Androgen receptors in hormone-dependent and castration-resistant prostate cancer," Pharmacology \& Therapeutics, vol. 140, no. 3, pp. 223-238, 2013.

[96] S. Koochekpour, "Androgen receptor signaling and mutations in prostate cancer," Asian Journal of Andrology, vol. 12, no. 5, pp. 639-657, 2010.

[97] S. M. Dehm and D. J. Tindall, "Molecular regulation of androgen action in prostate cancer," Journal of Cellular Biochemistry, vol. 99, no. 2, pp. 333-344, 2006.

[98] E. Jernberg, A. Bergh, and P. Wikström, "Clinical relevance of androgen receptor alterations in prostate cancer," Endocrine Connections, vol. 6, no. 8, pp. R146-R161, 2017.

[99] N. Nadiminty, R. Tummala, C. Liu et al., "NF-B2/p52 induces resistance to enzalutamide in prostate cancer: role of androgen receptor and its variants," Molecular Cancer Therapeutics, vol. 12, no. 8, pp. 1629-1637, 2013.

[100] E. A. Mostaghel, B. T. Marck, S. R. Plymate et al., "Resistance to CYP17A1 inhibition with abiraterone in castration-resistant prostate cancer: induction of steroidogenesis and androgen receptor splice variants," Clinical Cancer Research, vol. 17, no. 18, pp. 5913-5925, 2011.

[101] R. Hu, T. A. Dunn, S. Wei et al., "Ligand-independent androgen receptor variants derived from splicing of cryptic exons signify hormone-refractory prostate cancer," Cancer Research, vol. 69, no. 1, pp. 16-22, 2009.

[102] Z. Guo, X. Yang, F. Sun et al., “A novel androgen receptor splice variant is up-regulated during prostate cancer progression and promotes androgen depletion-resistant growth," Cancer Research, vol. 69, no. 6, pp. 2305-2313, 2009.

[103] A. Abeshouse, J. Ahn, R. Akbani et al., "The molecular taxonomy of primary prostate cancer," Cell, vol. 163, no. 163, pp. 1011-1025, 2015.

[104] C. Lu and J. Luo, "Decoding the androgen receptor splice variants," Translational Andrology and Urology, vol. 2, no. 3, p. 178, 2013.

[105] Y. Li, S. C. Chan, L. J. Brand, T. H. Hwang, K. A. T. Silverstein, and S. M. Dehm, “Androgen receptor splice variants mediate enzalutamide resistance in castration-resistant prostate cancer cell lines," Cancer Research, vol. 73, no. 2, pp. 483-489, 2013.

[106] B. Cao, G. Zhang, D. Xu et al., “Androgen receptor splice variants activating the full-length receptor in mediating resistance to androgen-directed therapy," Oncotarget, vol. 5, no. 6, p. 1646, 2014.

[107] D. Xu, Y. Zhan, Y. Qi et al., "Androgen receptor splice variants dimerize to transactivate target genes," Cancer Research, vol. 75, no. 17, pp. 3663-3671, 2015.

[108] Y. Qu, B. Dai, D. Ye et al., "Constitutively active AR-V7 plays an essential role in the development and progression of castration-resistant prostate cancer," Scientific Reports, vol. 5, p. 7654, 2015.

[109] M.-L. Zhu and N. Kyprianou, "Role of androgens and the androgen receptor in epithelial-mesenchymal transition and invasion of prostate cancer cells," The FASEB Journal, vol. 24, no. 3, pp. 769-777, 2010.

[110] Y. Sun, B.-E. Wang, K. G. Leong et al., "Androgen deprivation causes epithelial-mesenchymal transition in the prostate: implications for androgen-deprivation therapy," Cancer Research, vol. 72, no. 2, pp. 527-536, 2012.

[111] G. J. Klarmann, E. M. Hurt, L. A. Mathews et al., "Invasive prostate cancer cells are tumor initiating cells that have a stem cell-like genomic signature," Clinical \& Experimental Metastasis, vol. 26, no. 5, pp. 433-446, 2009.

[112] D. Kong, S. Banerjee, A. Ahmad et al., "Epithelial to mesenchymal transition is mechanistically linked with stem cell signatures in prostate cancer cells," PLoS One, vol. 5, no. 8, Article ID e12445, 2010.

[113] S. A. Mani, W. Guo, M.-J. Liao et al., "The epithelial-mesenchymal transition generates cells with properties of stem cells," Cell, vol. 133, no. 4, pp. 704-715, 2008.

[114] M. Santisteban, J. M. Reiman, M. K. Asiedu et al., "Immuneinduced epithelial to mesenchymal transition in vivo generates breast cancer stem cells," Cancer Research, vol. 69, no. 7, pp. 2887-2895, 2009.

[115] X. Zhang, C. Morrissey, S. Sun et al., "Androgen receptor variants occur frequently in castration resistant prostate cancer metastases," PLoS One, vol. 6, no. 11, Article ID e27970, 2011.

[116] P. A. Watson, Y. F. Chen, M. D. Balbas et al., "Constitutively active androgen receptor splice variants expressed in castration-resistant prostate cancer require full-length androgen receptor," Proceedings of the National Academy of Sciences, vol. 107, no. 39, pp. 16759-16765, 2010.

[117] S. Sun, C. C. T. Sprenger, R. L. Vessella et al., "Castration resistance in human prostate cancer is conferred by a frequently occurring androgen receptor splice variant," Journal of Clinical Investigation, vol. 120, no. 8, pp. 2715-2730, 2010.

[118] M. Marín-Aguilera, J. Codony-Servat, Ò. Reig et al., "Epithelial-to-mesenchymal transition mediates docetaxel resistance and high risk of relapse in prostate cancer," Molecular Cancer Therapeutics, vol. 13, no. 5, pp. 1270-1284, 2014.

[119] X. Wang, M. K.-d. Julio, K. D. Economides et al., "A luminal epithelial stem cell that is a cell of origin for prostate cancer," Nature, vol. 461, no. 7263, pp. 495-500, 2009.

[120] C.-L. Chen, D. Mahalingam, P. Osmulski et al., "Single-cell analysis of circulating tumor cells identifies cumulative expression patterns of EMT-related genes in metastatic prostate cancer," The Prostate, vol. 73, no. 8, pp. 813-826, 2013. 
[121] A. J. Armstrong, M. S. Marengo, S. Oltean et al., "Circulating tumor cells from patients with advanced prostate and breast cancer display both epithelial and mesenchymal markers," Molecular Cancer Research, vol. 9, no. 8, pp. 997-1007, 2011.

[122] D. T. Miyamoto, R. J. Lee, S. L. Stott et al., "Androgen receptor signaling in circulating tumor cells as a marker of hormonally responsive prostate cancer," Cancer Discovery, vol. 2, no. 11, pp. 995-1003, 2012.

[123] E. G. Bluemn, I. M. Coleman, J. M. Lucas et al., “Androgen receptor pathway-independent prostate cancer is sustained through FGF signaling," Cancer Cell, vol. 32, no. 4, pp. 474-489, 2017.

[124] A. Komiya, K. Yasuda, A. Watanabe, Y. Fujiuchi, T. Tsuzuki, and H. Fuse, "The prognostic significance of loss of the androgen receptor and neuroendocrine differentiation in prostate biopsy specimens among castration-resistant prostate cancer patients," Molecular and Clinical Oncology, vol. 1, no. 2, pp. 257-262, 2013.

[125] M. Crumbaker, L. Khoja, and A. Joshua, "AR signaling and the PI3K pathway in prostate cancer," Cancers, vol. 9, no. 12, p. 34, 2017.

[126] T. Jamaspishvili, D. M. Berman, A. E. Ross et al., "Clinical implications of PTEN loss in prostate cancer," Nature Reviews Urology, vol. 15, no. 4, pp. 222-234, 2018.

[127] B. S. Carver, C. Chapinski, J. Wongvipat et al., "Reciprocal feedback regulation of PI3K and androgen receptor signaling in PTEN-deficient prostate cancer," Cancer Cell, vol. 19, no. 5, pp. 575-586, 2011.

[128] D. J. Mulholland, L. M. Tran, Y. Li et al., "Cell autonomous role of PTEN in regulating castration-resistant prostate cancer growth," Cancer Cell, vol. 19, no. 6, pp. 792-804, 2011.

[129] H. Murillo, H. Huang, L. J. Schmidt, D. I. Smith, and D. J. Tindall, "Role of PI3K signaling in survival and progression of $\mathrm{LNCaP}$ prostate cancer cells to the androgen refractory state," Endocrinology, vol. 142, no. 11, pp. 4795-4805, 2001.

[130] S. H. Lee, D. Johnson, R. Luong, and Z. Sun, "Crosstalking between androgen and PI3K/AKT signaling pathways in prostate cancer cells," Journal of Biological Chemistry, vol. 290, no. 5, pp. 2759-2768, 2015.

[131] K. Choucair, J. Ejdelman, F. Brimo, A. Aprikian, S. Chevalier, and J. Lapointe, "PTEN genomic deletion predicts prostate cancer recurrence and is associated with low AR expression and transcriptional activity," $B M C$ Cancer, vol. 12, no. 1, p. 543, 2012.

[132] S. Ha, R. Ruoff, N. Kahoud, T. F. Franke, and S. K. Logan, "Androgen receptor levels are upregulated by Akt in prostate cancer," Endocrine Related Cancer, vol. 18, no. 2, pp. 245255, 2011.

[133] K. Sircar, M. Yoshimoto, F. A. Monzon et al., "PTENgenomic deletion is associated with p-Akt and AR signalling in poorer outcome, hormone refractory prostate cancer," The Journal of Pathology, vol. 218, no. 4, pp. 505-513, 2009.

[134] M. Kaarbø, Ø. L. Mikkelsen, L. Malerød et al., "PI3K-AKTmTOR pathway is dominant over androgen receptor signaling in prostate cancer cells," Analytical Cellular Pathology, vol. 32, Article ID 290643, 17 pages, 2010.

[135] Y. Wang, T. Romigh, X. He et al., "Differential regulation of PTEN expression by androgen receptor in prostate and breast cancers," Oncogene, vol. 30, no. 42, pp. 4327-4338, 2011.

[136] D. J. Mulholland, N. Kobayashi, M. Ruscetti et al., "Pten loss and RAS/MAPK activation cooperate to promote EMT and metastasis initiated from prostate cancer stem/progenitor cells," Cancer Research, vol. 72, no. 7, pp. 1878-1889, 2012.

[137] L.-B. Song, J. Li, W.-T. Liao et al., "The polycomb group protein Bmi-1 represses the tumor suppressor PTEN and induces epithelial-mesenchymal transition in human nasopharyngeal epithelial cells," Journal of Clinical Investigation, vol. 119, no. 12, pp. 3626-3636, 2009.

[138] F. K. Collak, U. Demir, and F. Sagir, "YAP1 is involved in tumorigenic properties of prostate cancer cells," Pathology \& Oncology Research, 2019.

[139] W. Xu, Z. Yang, C. Xie et al., "PTEN lipid phosphatase inactivation links the hippo and PI3K/Akt pathways to induce gastric tumorigenesis," Journal of Experimental \& Clinical Cancer Research, vol. 37, no. 1, p. 198, 2018.

[140] B. A. Edgar, "From cell structure to transcription: hippo forges a new path," Cell, vol. 124, no. 2, pp. 267-273, 2006.

[141] F.-X. Yu, B. Zhao, and K.-L. Guan, "Hippo pathway in organ size control, tissue homeostasis, and cancer," Cell, vol. 163, no. 4, pp. 811-828, 2015.

[142] B. Zhao, X. Wei, W. Li et al., "Inactivation of YAP oncoprotein by the Hippo pathway is involved in cell contact inhibition and tissue growth control," Genes \& Development, vol. 21, no. 21, pp. 2747-2761, 2007.

[143] Q.-Y. Lei, H. Zhang, B. Zhao et al., "TAZ promotes cell proliferation and epithelial-mesenchymal transition and is inhibited by the hippo pathway," Molecular and Cellular Biology, vol. 28, no. 7, pp. 2426-2436, 2008.

[144] D. Zhou, C. Conrad, F. Xia et al., "Mst1 and Mst2 maintain hepatocyte quiescence and suppress hepatocellular carcinoma development through inactivation of the Yap1 oncogene," Cancer Cell, vol. 16, no. 5, pp. 425-438, 2009.

[145] B. Zhao, X. Ye, J. Yu et al., "TEAD mediates YAP-dependent gene induction and growth control," Genes \& Development, vol. 22, no. 14, p. 000, 2008.

[146] S. Wu, Y. Liu, Y. Zheng, J. Dong, and D. Pan, "The TEAD/ TEF family protein Scalloped mediates transcriptional output of the Hippo growth-regulatory pathway," Developmental Cell, vol. 14, no. 3, pp. 388-398, 2008.

[147] W. Kang, J. H. M. Tong, A. W. H. Chan et al., "Yes-associated protein 1 exhibits oncogenic property in gastric cancer and its nuclear accumulation associates with poor prognosis," Clinical Cancer Research, vol. 17, no. 8, pp. 2130-2139, 2011.

[148] S. E. Lee, J. U. Lee, M. H. Lee et al., "RAF kinase inhibitorindependent constitutive activation of Yes-associated protein 1 promotes tumor progression in thyroid cancer," Oncogenesis, vol. 2, no. 7, p. e55, 2013.

[149] C. M. Xu, W. W. Liu, C. J. Liu, C. Wen, H. F. Lu, and F. S. Wan, "Mst1 overexpression inhibited the growth of human non-small cell lung cancer in vitro and in vivo," Cancer Gene Therapy, vol. 20, no. 8, pp. 453-460, 2013.

[150] W. M. Konsavage, S. L. Kyler, S. A. Rennoll, G. Jin, and G. S. Yochum, "Wnt $/ \beta$-catenin signaling regulates Yes-associated protein (YAP) gene expression in colorectal carcinoma cells," Journal of Biological Chemistry, vol. 287, no. 15, pp. 11730-11739, 2012.

[151] L. Ge, M. Smail, W. Meng et al., "Yes-associated protein expression in head and neck squamous cell carcinoma nodal metastasis," PLoS One, vol. 6, no. 11, Article ID e27529, 2011.

[152] A. A. Steinhardt, M. F. Gayyed, A. P. Klein et al., "Expression of Yes-associated protein in common solid tumors," Human Pathology, vol. 39, no. 11, pp. 1582-1589, 2008.

[153] C. Wang, L Zhang, Q He et al., "Differences in Yes-associated protein and mRNA levels in regenerating liver and 
hepatocellular carcinoma," Molecular Medicine Reports, vol. 5, no. 5, pp. 410-414, 2012.

[154] N. Jiang, K. Hjorth-Jensen, O. Hekmat et al., "In vivo quantitative phosphoproteomic profiling identifies novel regulators of castration-resistant prostate cancer growth," Oncogene, vol. 34, no. 21, pp. 2764-2776, 2015.

[155] G. Kuser-Abali, A. Alptekin, M. Lewis, I. P. Garraway, and B. Cinar, "YAP1 and AR interactions contribute to the switch from androgen-dependent to castration-resistant growth in prostate cancer," Nature Communications, vol. 6, p. 8126, 2015.

[156] M. Overholtzer, J. Zhang, G. A. Smolen et al., “Transforming properties of YAP, a candidate oncogene on the chromosome 11q22 amplicon," Proceedings of the National Academy of Sciences, vol. 103, no. 33, pp. 12405-12410, 2006.

[157] R. Liu, S. Huang, Y. Lei et al., "FGF8 promotes colorectal cancer growth and metastasis by activating YAP1," Oncotarget, vol. 6, no. 2, p. 935, 2015.

[158] Q. Hu, C. Li, S. Wang et al., "LncRNAs-directed PTEN enzymatic switch governs epithelial-mesenchymal transition," Cell Research, vol. 29, no. 4, pp. 286-304, 2019.

[159] M. Yu, Y. Chen, X. Li et al., "YAP1 contributes to NSCLC invasion and migration by promoting Slug transcription via the transcription co-factor TEAD," Cell Death \& Disease, vol. 9, no. 5, p. 464, 2018.

[160] Y. Tang, T. Feinberg, E. T. Keller, X.-Y. Li, and S. J. Weiss, "Snail/slug binding interactions with YAP/TAZ control skeletal stem cell self-renewal and differentiation," Nature Cell Biology, vol. 18, no. 9, pp. 917-929, 2016.

[161] Y. Wang, J. Liu, X. Ying, P. C. Lin, and B. P. Zhou, “Twistmediated epithelial-mesenchymal transition promotes breast tumor cell invasion via inhibition of hippo pathway," Scientific Reports, vol. 6, p. 24606, 2016.

[162] S. C. Wei, L. Fattet, J. H. Tsai et al., "Matrix stiffness drives epithelial-mesenchymal transition and tumour metastasis through a TWIST1-G3BP2 mechanotransduction pathway," Nature Cell Biology, vol. 17, no. 5, pp. 678-688, 2015.

[163] C. Morgan, S. A. Jenkins, H. G. Kynaston, and S. H. Doak, "The role of adhesion molecules as biomarkers for the aggressive prostate cancer phenotype," PLoS One, vol. 8, no. 12, Article ID e81666, 2013.

[164] A. J. Knights, A. P Funnell, M Crossley, and R. C Pearson, "Holding tight: cell junctions and cancer spread," Trends in Cancer Research, vol. 8, no. 8, pp. 61-69, 2012.

[165] S. Tuomi, A. Mai, J. Nevo et al., "PKC regulation of an 5 integrin-ZO-1 complex controls lamellae formation in migrating cancer cells," Science Signaling, vol. 2, no. 77, p. ra32, 2009.

[166] K. S. M. Smalley, P. Brafford, N. K. Haass, J. M. Brandner, E. Brown, and M. Herlyn, "Up-regulated expression of zonula occludens protein-1 in human melanoma associates with $\mathrm{N}$-cadherin and contributes to invasion and adhesion," The American Journal of Pathology, vol. 166, no. 5, pp. 1541-1554, 2005.

[167] B. Dekky, M. Ruff, D. Bonnier, V. Legagneux, and N. Théret, "Correction: proteomic screening identifies the zonula occludens protein ZO-1 as a new partner for ADAM12 in invadopodia-like structures," Oncotarget, vol. 9, no. 87, p. 35795, 2018.

[168] W. Lehmann, D. Mossmann, J. Kleemann et al., “ZEB1 turns into a transcriptional activator by interacting with YAP1 in aggressive cancer types," Nature Communications, vol. 7, no. 1, p. 10498, 2016.
[169] L. A. Selth, R. Das, S. L. Townley et al., "A ZEB1-miR-375YAP1 pathway regulates epithelial plasticity in prostate cancer," Oncogene, vol. 36, no. 1, pp. 24-34, 2017.

[170] H. Chen, Q. Chen, and Q. Luo, "Expression of netrin-1 by hypoxia contributes to the invasion and migration of prostate carcinoma cells by regulating YAP activity," Experimental Cell Research, vol. 349, no. 2, pp. 302-309, 2016.

[171] J. Park, D.-H. Kim, S. R. Shah et al., "Switch-like enhancement of epithelial-mesenchymal transition by YAP through feedback regulation of WT1 and Rho-family GTPases," Nature Communications, vol. 10, no. 1, p. 2797, 2019.

[172] K. Tumaneng, K. Schlegelmilch, R. C. Russell et al., "YAP mediates crosstalk between the Hippo and PI(3)K-TOR pathways by suppressing PTEN via miR-29," Nature Cell Biology, vol. 14, no. 12, pp. 1322-1329, 2012

[173] H.-K. Lin, Y.-C. Hu, D. K. Lee, and C. Chang, "Regulation of androgen receptor signaling by PTEN (phosphatase and tensin homolog deleted on chromosome 10) tumor suppressor through distinct mechanisms in prostate cancer cells," Molecular Endocrinology, vol. 18, no. 10, pp. 2409-2423, 2004.

[174] T. M. Becker, N. J. Caixeiro, S. H. Lim et al., "New frontiers in circulating tumor cell analysis: a reference guide for biomolecular profiling toward translational clinical use," International Journal of Cancer, vol. 134, no. 11, pp. 25232533, 2014.

[175] M. Thalgott, B. Rack, T. Maurer et al., "Detection of circulating tumor cells in different stages of prostate cancer," Journal of Cancer Research and Clinical Oncology, vol. 139, no. 5, pp. 755-763, 2013.

[176] J. W. Po, A. Roohullah, D. Lynch et al., "Improved ovarian cancer EMT-CTC isolation by immunomagnetic targeting of epithelial EpCAM and mesenchymal N-cadherin," Journal of Circulating Biomarkers, vol. 7, 2018.

[177] H. Polioudaki, S. Agelaki, R. Chiotak et al., "Variable expression levels of keratin and vimentin reveal differential EMT status of circulating tumor cells and correlation with clinical characteristics and outcome of patients with metastatic breast cancer," BMC Cancer, vol. 15, p. 399, 2015.

[178] Y. Horimoto, E. Tokuda, F. Murakami et al., "Analysis of circulating tumour cell and the epithelial mesenchymal transition (EMT) status during eribulin-based treatment in 22 patients with metastatic breast cancer: a pilot study," Journal of Translational Medicine, vol. 16, no. 1, p. 287, 2018.

[179] X.-H. Zhao, Z.-R. Wang, C.-L. Chen et al., "Molecular detection of epithelial-mesenchymal transition markers in circulating tumor cells from pancreatic cancer patients: potential role in clinical practice," World Journal of Gastroenterology, vol. 25, no. 1, pp. 138-150, 2019.

[180] J. W. Po, D. Lynch, P. de Souza, and T. M. Becker, "Importance and detection of epithelial-to-mesenchymal transition (EMT) phenotype in CTCs," in Tumor Metastasis, pp. 241-256, InTechOpen, London, UK, 2016.

[181] L.-N. Qi, B.-D. Xiang, F.-X. Wu et al., "Circulating tumor cells undergoing EMT provide a metric for diagnosis and prognosis of patients with hepatocellular carcinoma," Cancer Research, vol. 78, no. 16, pp. 4731-4744, 2018.

[182] A. J. Armstrong, S. Halabi, J. Luo et al., "Prospective multicenter validation of androgen receptor splice variant 7 and hormone therapy resistance in high-risk castration-resistant prostate cancer: the PROPHECY study," Journal of Clinical Oncology, vol. 37, no. 13, pp. 1120-1129, 2019. 
[183] M. A. Leversha, J. Han, Z. Asgari et al., "Fluorescence in situ hybridization analysis of circulating tumor cells in metastatic prostate cancer," Clinical Cancer Research, vol. 15, no. 6, pp. 2091-2097, 2009.

[184] J. Steinestel, M. Luedeke, A. Arndt et al., "Detecting predictive androgen receptor modifications in circulating prostate cancer cells," Oncotarget, vol. 10, no. 41, pp. 4213-4223, 2019.

[185] E. E. Reyes, D. J. VanderWeele, M. Isikbay et al., "Quantitative characterization of androgen receptor protein expression and cellular localization in circulating tumor cells from patients with metastatic castration-resistant prostate cancer," Journal of Translational Medicine, vol. 12, no. 1, p. 313,2014

[186] M. S. Darshan, M. S. Loftus, M. Thadani-Mulero et al., "Taxane-induced blockade to nuclear accumulation of the androgen receptor predicts clinical responses in metastatic prostate cancer," Cancer Research, vol. 71, no. 18, pp. 6019-6029, 2011.

[187] E. S. Antonarakis, C. Lu, H. Wang et al., "AR-V7 and resistance to enzalutamide and abiraterone in prostate cancer," New England Journal of Medicine, vol. 371, no. 11, pp. 1028-1038, 2014.

[188] A. Sharp, I Coleman, W Yuan et al., "Androgen receptor splice variant-7 expression emerges with castration resistance in prostate cancer," The Journal of Clinical Investigation, vol. 129, no. 129, pp. 192-208, 2019.

[189] M. Nimir, Y. Ma, S. A. Jeffreys et al., "Detection of AR-V7 in liquid biopsies of castrate resistant prostate cancer patients: a comparison of AR-V7 analysis in circulating tumor cells, circulating tumor RNA and exosomes," Cells, vol. 8, no. 7, p. $688,2019$.

[190] A. Luk, Y. Ma, P. Ding et al., "CTC-mRNA (AR-V7) analysis from blood samples-impact of blood collection tube and storage time," International Journal of Molecular Sciences, vol. 18, no. 5, p. 1047, 2017.

[191] H. I. Scher, R. P. Graf, N. A. Schreiber et al., "Nuclearspecific AR-V7 protein localization is necessary to guide treatment selection in metastatic castration-resistant prostate cancer," European Urology, vol. 71, no. 6, pp. 874-882, 2017.

[192] H. I. Scher, D. Lu, N. A. Schreiber et al., "Association of ARV7 on circulating tumor cells as a treatment-specific biomarker with outcomes and survival in castration-resistant prostate cancer," JAMA Oncology, vol. 2, no. 11, pp. 1441-1449, 2016.

[193] D. Worroll, G. Galletti, A. Gjyrezi et al., "Androgen receptor nuclear localization correlates with AR-V7 mRNA expression in circulating tumor cells (CTCs) from metastatic castration resistance prostate cancer patients," Physical Biology, vol. 16, no. 3, Article ID 036003, 2019.

[194] G. Attard, J. F. Swennenhuis, D. Olmos et al., "Characterization of ERG, AR and PTEN gene status in circulating tumor cells from patients with castration-resistant prostate cancer," Cancer Research, vol. 69, no. 7, pp. 2912-2918, 2009.

[195] M. Maas, M. Hegemann, S. Rausch, J. Bedke, A. Stenzl, and T. Todenhöfer, "Circulating tumor cells and their role in prostate cancer," Asian Journal of Andrology, vol. 21, no. 1, p. 24, 2019.

[196] M. Bredemeier, S. Kasimir-Bauer, H.-C. Kolberg et al., "Comparison of the PI3KCA pathway in circulating tumor cells and corresponding tumor tissue of patients with metastatic breast cancer," Molecular Medicine Reports, vol. 15, no. 5, pp. 2957-2968, 2017.
[197] Y. Gao, X. Ni, H. Guo et al., "Single-cell sequencing deciphers a convergent evolution of copy number alterations from primary to circulating tumor cells," Genome Research, vol. 27, no. 8, pp. 1312-1322, 2017.

[198] J. Zhang, K. Chen, and Z. Fan, "Circulating tumor cell isolation and analysis," in Advances in Clinical Chemistry, pp. 1-31, Elsevier, Amsterdam, The Netherlands, 2016.

[199] D. T. Ting, B. S. Wittner, M. Ligorio et al., "Single-cell RNA sequencing identifies extracellular matrix gene expression by pancreatic circulating tumor cells," Cell Reports, vol. 8, no. 6, pp. 1905-1918, 2014.

[200] S. Sharma, R. Zhuang, M. Long et al., "Circulating tumor cell isolation, culture, and downstream molecular analysis," Biotechnology Advances, vol. 36, no. 4, pp. 1063-1078, 2018.

[201] G. Kallergi, D. Mavroudis, V. Georgoulias, and C. Stournaras, "Phosphorylation of FAK, PI-3K, and impaired actin organization in CK-positive micrometastatic breast cancer cells," Molecular Medicine, vol. 13, no. 1-2, pp. 79-88, 2007.

[202] I. Tinhofer, T. Hristozova, C. Stromberger, U. KeilhoIz, and V. Budach, "Monitoring of circulating tumor cells and their expression of EGFR/phospho-EGFR during combined radiotherapy regimens in locally advanced squamous cell carcinoma of the head and neck," International Journal of Radiation Oncology*Biolog $y *$ Physics, vol. 83, no. 5, pp. e685-e690, 2012

[203] K. Yokoi, D. Hawke, C. J. Oborn et al., "Identification and validation of SRC and phospho-SRC family proteins in circulating mononuclear cells as novel biomarkers for pancreatic cancer," Translational Oncology, vol. 4, no. 2, pp. 83-91, 2011.

[204] S. J. Shin, J. W. Hwang, J. B. Ahn, S. Y. Rha, J. K. Roh, and H. C. Chung, "Circulating vascular endothelial growth factor receptor 2/pAkt-positive cells as a functional pharmacodynamic marker in metastatic colorectal cancers treated with antiangiogenic agent," Investigational New Drugs, vol. 31, no. 1, pp. 1-13, 2013. 